\title{
Costus spp e sua relevância medicinal: Uma revisão integrativa
}

\author{
Costus spp and its medicinal relevance: An integrative review \\ Costus spp y su relevancia medicinal: Una revisión integradora
}

\section{Resumo}

Objetivo: o presente estudo realizou uma revisão integrativa visando avaliar os aspectos químicos de espécies pertencentes ao gênero Costus, bem como de estudos que avaliaram as atividades biológicas. Metodologia: Inicial levantamento bibliográfico em PUBMED e SCOPUS, utilizando strings "Costus AND medicine pharmacological". Foram lidos títulos e resumos, sendo selecionados de acordo com critérios de elegibilidade. Na segunda etapa, realizou-se a leitura dos artigos na integras e excluídos os artigos que não estiveram de acordo com critérios de inclusão. Resultados: Foram incluídos 21 artigos, tendo relação com informações fitoquímicas e diferentes atividades biológicas. Espécies do gênero Costus demonstraram atividades promissoras para o tratamento da inflamação, dor, diabetes e nefrolitíase, tendo relação com algumas alegações de uso popular. Considerações finais: Em síntese, espécies pertencentes ao gênero Costus são promissoras em termos medicinais, sendo necessários outros ensaios que avaliem a segurança dos compostos presentem nas espécies do gênero para futuros ensaios clínicos.

Palavras-chave: Costus; Uso popular; Anti-inflamatório; Antidiabetes; Urolítico.

\begin{abstract}
Aim: the present study carried out an integrative review aiming to evaluate the chemical aspects of species belonging to the Costus genus, as well studies that evaluated the biological activities. Methods: Initial bibliographic survey in PUBMED and SCOPUS, using strings "Costus AND medicine pharmacological". Titles and abstracts were read and selected according to eligibility criteria. In the second stage, the articles were full read and articles that did not meet the inclusion criteria were excluded. Results: Twenty-one articles were included, relating to phytochemical information and different biological activities. Species of the Costus have shown promising activities for the treatment of inflammation, pain, diabetes and nephrolithiasis, in connection with some claims of popular use. Final considerations: In summary, species belonging to the genus Costus are promising in medicinal terms, requiring further tests to assess the safety of the compounds present in the species of the genus for future clinical trials.
\end{abstract}

Keywords: Costus; Popular use; Anti-inflammatory; Antidiabetes; Urolytic.

\section{Resumen}

Objetivo: el presente estudio realizó una revisión integrativa con el objetivo de evaluar los aspectos químicos de especies pertenecientes al género Costus, así como estudios que evaluaron las actividades biológicas. Metodología: Encuesta bibliográfica inicial en PUBMED y SCOPUS, utilizando cadenas "Costus Y medicina farmacológica". Los 
títulos y resúmenes se leyeron y seleccionaron de acuerdo con los criterios de elegibilidad. En la segunda etapa, los artículos se leyeron íntegramente y se excluyeron los artículos que no cumplían con los criterios de inclusión. Resultados: se incluyeron 21 artículos relacionados con información fitoquímica y diferentes actividades biológicas. Las especies del género Costus han mostrado actividades prometedoras para el tratamiento de la inflamación, el dolor, la diabetes y la nefrolitiasis, en relación con algunas afirmaciones de uso popular. Consideraciones finales: En resumen, las especies pertenecientes al género Costus son prometedoras en términos medicinales, requiriendo más pruebas para evaluar la seguridad de los compuestos presentes en las especies del género para futuros ensayos clínicos.

Palabras clave: Costus; Uso popular; Antiinflamatorio; Anti-diabetes; Urolítico.

\section{Introdução}

No Brasil, plantas medicinais são encontradas em comércios de centros urbanos, onde diversos tipos de plantas são comercializados para propósitos terapêuticos. O acesso limitado à medicina especializada e o crescente interesse pelos chamados tratamentos naturais explicam a rápida difusão do conhecimento empírico acerca de plantas medicinais (Cavalcanti \& Albuquerque, 2013).

Atrelado a isso, há uma suposição de que as plantas medicinais e produtos derivados não apresentam risco à saúde, sendo um conceito difundido sem embasamento científico que acaba por oferecer sérios riscos à saúde de pessoas menos esclarecidas. Como consequência, ocorre o uso inadequado e despreocupado, com possíveis riscos agravados pela falta de informações fidedignas sobre os potenciais efeitos tóxicos, até mesmo em associações com medicamentos de uso tradicionais (Brasil, 2019).

Entretanto, o uso seguro de plantas medicinais e fitoterápicos é assegurando através de legislações regulamentarias advindas de órgão público específico que promove a proteção da saúde da população. A Agência Nacional de Vigilância Sanitária possui normas específicas que garantem a segurança e eficácia de plantas medicinais, drogas vegetais e medicamentos fitoterápicos (Brasil, 1999).

Nesse sentido, diversos estudos etnobotânicos identificaram vários usos populares para as plantas do gênero Costus, pertencente à família Costaceae. As espécies do gênero crescem em áreas tropicais e subtropicais, em florestas pluviais e em outros ambientes úmidos, possuem baixa densidade e possuem um alto período de floração (Araújo \& Oliveira, 2007).

Popularmente, as espécies são conhecidas como: cana-mansa, canarana, cana-de-macaco, pobre-velho e cana-dobrejo. Quanto ao uso popular, o chá da espécie Costus spicatus (Jacq.) Sw é utilizada como: adstringente, depurativa, diurética, no tratamento de gonorreia, de sífilis, de nefrites e de diabetes (Paes, Mendonça \& Casas, 2013). A espécie Costus spiralis tem sido relatada como um agente antimicrobiano, antifúngico, antioxidante, leishmanicida, anti-inflamatória e imunomoduladora, diurética, ureolítica e para disfunção renal (Duarte, Andrade \& Oliveira, 2017). Alguns estudos químicos levaram ao isolamento de metabólitos, bem como demonstraram a atividade farmacológica de espécies pertencentes a este gênero (Singh et al., 2014; Anyasor, Onajobi, Osilesi, Adebawo, \& Oboutor, 2014). Mediante exposto, o presente estudo realizou uma revisão integrativa visando avaliar os aspectos químicos de espécies pertencentes ao gênero Costus, bem como de estudos que avaliaram as atividades biológicas.

\section{Metodologia}

Este trabalho utilizou o método descritivo, em que artigos publicados foram compilados e posteriormente avaliados em pares acerca da relação das atividades testadas com o uso medicinal, bem como dos aspectos químicos, de espécies do gênero Costus, pela população brasileira (Pereira, Shitsuka, Parreira \& Shitsuka, 2018).

Realizou-se inicialmente investigação bibliográfica, dos últimos 10 anos, sobre os potenciais medicinal e farmacológico do gênero Costus, através das bases de dados PUBMED e SCOPUS. Para a pesquisa, utilizou-se das strings 
"Costus AND medicine pharmacological" onde foram encontrados 54 artigos na plataforma PUBMED e 37 na plataforma SCOPUS, revisados por pares. Após leitura de título e resumo, foram selecionados 45 artigos (PUBMED N=33; SCOPUS $\mathrm{n}=12$ ) para receber os critérios de elegibilidade. Os artigos não poderiam ser artigo de revisão, deveriam abordar somente espécie do gênero Costus e em caso de duplicação, ser escolhido o presente na base de dados com maior número de artigos encontrados. Após a aplicação desses critérios, 31 artigos (PUBMED n=28; SCOPUS n=3) passaram por uma segunda seleção onde os trabalhos foram lidos na íntegra, sempre aplicando os critérios de qualidade para decidir, junto aos outros autores, quais artigos estariam inclusos permanentemente (Figura 1; PUBMED n=18; SCOPUS n=3). Os 21 artigos inclusos neste estudo testaram in vivo e in vitro hipóteses atreladas aos principais usos populares das espécies do gênero Costus (antiinflamatório, antidiabético, urolítico e antimicrobiano), relatavam informações fitoquímicas de espécies do gênero Costus e eram artigos originais.

Uma síntese de cada artigo foi feita, sempre evidenciando os pontos relevantes para a revisão. A extração dos dados se organizou por meio de tabela em programa Excel Office 365, onde foram elencadas as seguintes informações: título do artigo, espécie utilizada, objetivo, metodologia, síntese dos resultados, conclusão e referência.

Figura 1. Fluxograma de seleção de artigos segundo bases de dados.

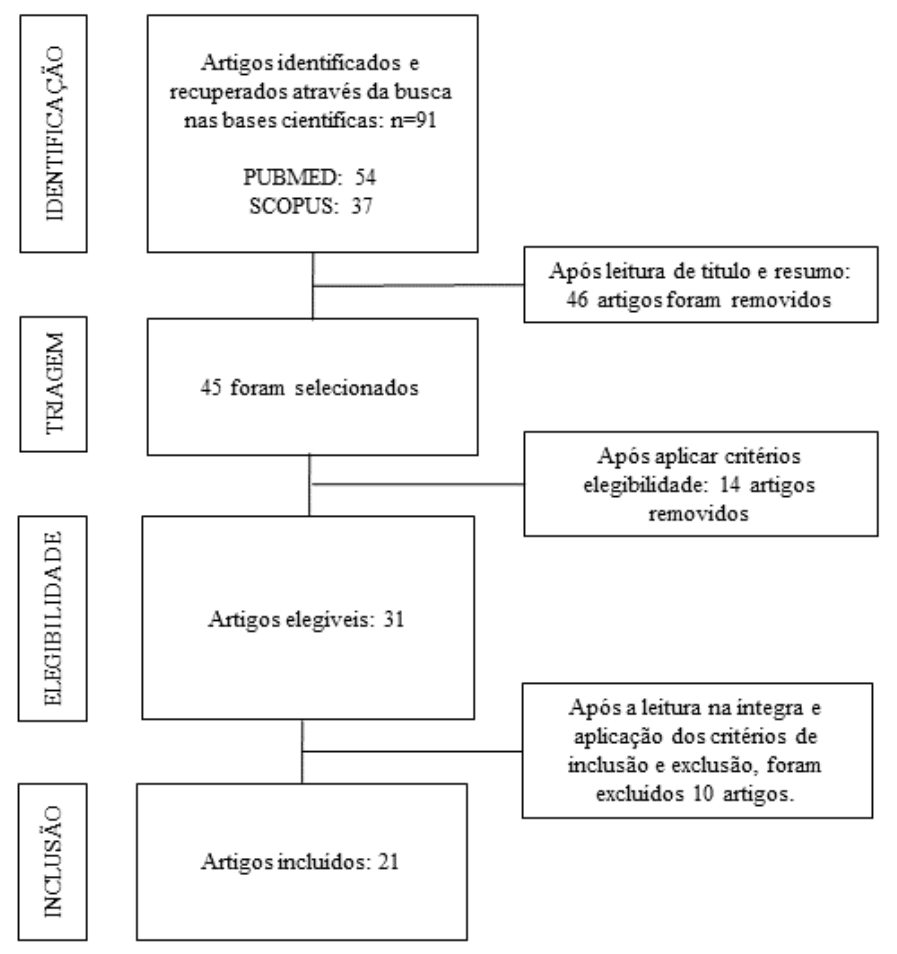

Fonte: Autores (2021).

\section{Resultados e Discussão}

Na busca realizada nas bases de dados PUBMED e SCOPUS foram encontrados, respectivamente, 54 e 37 artigos. Sendo 45 artigos relacionados às strings em ambas as bases. Após a leitura dos títulos e resumos dos artigos, percebeu-se que alguns artigos estavam presentes em ambas as plataformas, outros eram artigos que não trabalhavam somente com o gênero Costus sp., outros foram artigos de revisão e outros testavam atividades não relacionadas ao objetivo do presente trabalho.

No total, foram incluídos 21 artigos publicados em: 2010 (2 artigos), 2011 (1 artigo), 2012 (1 artigo), 2013 (1 artigo), 2014 (4 artigos), 2015 (4 artigos), 2016 (1 artigo), 2017 (1 artigo), 2018 ( 2 artigos), 2019 (1 artigo), 2020 (1 artigo) e 2021 (2 artigos), sendo esses artigos do ano de 2021 estudos feitos em 2020 e divulgados somente em 2021 (Tabela 1). 
Quanto às espécies utilizadas nos artigos: dois (9,5\%) utilizaram folhas de Costus afer, dois (9,5\%) utilizaram Costus arabicus, um (5\%) utilizou Costus igneus, um (5\%) utilizou Costus pictus, oito (38\%) utilizaram Costus speciosus, quatro (19\%) utilizaram Costus spicatus e três (14\%) utilizaram Costus spiralis. Quanto à distribuição dos artigos por tema: cinco (24\%) avaliaram a atividade antidiabética, sendo 2 in vivo (Eliza \& Daisy, 2010.; Ali, Almaghrabi \& Afifi., 2014) e 3 in vitro (Perera, Premadasa, \& Poongunran, 2015; Patibandla, Khan, MacGregor, Campbell \& Patterson, 2020; De Oliveira et al., 2018). Sobre os estudos que avaliaram atividade anti-inflamatória (33\%), seis estudos realizaram teste in vivo (Anyasor et al., 2014; Anyasor, Onajobi, Osilesi \& Adebawo, 2015; Al-Attas, El-Shaer, Mohamed, Ibrahim \& Esmat, 2015; Picanço et al., 2016; Quintans Júnior et al. 2010; De Farias Silva et al., 2021) e somente um realizou testes in vivo e in vitro (Krishnan, Mathew, Vijayalakshmi \& Helen et al., 2014).

Em relação aos estudos que avaliaram a atividade antimicrobiana, houve predominância de teste in vitro em todos os cinco (24\%) artigos (Cunha et al., 2011; Duraipandiyan, Al-Harbi, Ignacimuthu \& Muthukumar, 2012; Al-Kattan \& Khayyat, 2017; Ibrahim et al., 2019; Sousa et al., 2018). A atividade urolítica foi estudada em apenas dois $(9,5 \%)$ artigos através de métodos in vitro (De Cógáin et al., 2015; Moreno et al., 2021). O restante dos artigos (9,5\%) forneceu exclusivamente informações de prospecção fitoquímica (Paes, Mendonça \& Casas, 2013; Singh et al., 2014) que também serão consideradas para relevância medicinal do gênero. 
Tabela 1. Classificação dos artigos de acordo com espécie, títulos, ano de publicação, atividade e referências (2010-2021).

\begin{tabular}{|c|c|c|c|c|}
\hline Espécie & Título & Ano & Atividade biológica & Referências \\
\hline C. speciosus & Antioxidant activity of costunolide and eremanthin isolated from Costus speciosus (Koen ex. Retz) Sm & 2010 & Antidiabética & Eliza et al., 2010 \\
\hline C. speciosus & $\begin{array}{l}\text { Molecular mechanisms of anti-hyperglycemic effects of Costus speciosus extract in streptozotocin-induced } \\
\text { diabetic rats. }\end{array}$ & 2014 & Antidiabética & Ali et al., 2014. \\
\hline C. speciosus & $\alpha$-glucosidase and glycation inhibitory effects of Costus speciosus leaves & 2015 & Antidiabética & Perera et al., 2015 \\
\hline C. spiralis & Costus spiralis (Jacq.) Roscoe: A Novel Source of Flavones with $\alpha$-Glycosidase Inhibitory Activity & 2018 & Antidiabética & De Oliveira et al., 2018. \\
\hline C. pictus & $\begin{array}{l}\text { Costus pictus D. Don leaf extract stimulates GLP-1 secretion from GLUTag L-cells and has cytoprotective effects } \\
\text { in BRIN-BD11 } \beta \text {-cells }\end{array}$ & 2020 & Antidiabética & Patibandla et al., 2020. \\
\hline C. spicatus & Antinociceptive and anti-inflammatory effects of Costus spicatus in experimental animals & 2010 & Anti-inflamatória & Quintans Junior et al. 2010 \\
\hline C. afer & Anti-inflammatory and antioxidant activities of Costus afer Ker Gawl. hexane leaf fraction in arthritic rat models & 2014 & Anti-inflamatória & Anyasor et al., 2014 \\
\hline C. igneus & Anti-inflammatory potential of $\beta$-amyrin, a triterpenoid isolated from Costus igneus & 2014 & Anti-inflamatória & Krishnan et al., 2014 \\
\hline C. speciosus & Anti-inflammatory sesquiterpenes from Costus speciosus rhizomes & 2015 & Anti-inflamatória & Al-Attas et al., 2015 \\
\hline C. afer & Hematological and lipid profile evaluation of a hexane fraction of Costus afer leaves in arthritic rats & 2015 & Anti-inflamatória & Anyasor et al., 2015. \\
\hline C. spicatus & Pharmacological activity of Costus spicatus in experimental Bothrops atrox envenomation. & 2016 & Anti-inflamatória & Picanço et al., 2016. \\
\hline C. spiralis & Costus spiralis (Jacq.) Roscoe leaves fractions have potential to reduce effects of inflammatory diseases. & 2021 & Anti-inflamatória & De Farias Silva et al., 2021 \\
\hline C. arabicus & In vitro antibacterial, phototoxic, and synergistic activity of ethanol extracts from Costus cf. arabicus L & 2011 & Antimicrobiana & Cunha et al., 2011. \\
\hline C. speciosus & $\begin{array}{l}\text { Antimicrobial activity of sesquiterpene lactones isolated from traditional medicinal plant, Costus speciosus (Koen } \\
\text { ex.Retz.) Sm }\end{array}$ & 2012 & Antimicrobiana & Duraipandiyan et al., 2012 \\
\hline C. speciosus & Antimicrobial activity and chemical analyses of oil constituents of medicinal plant Costus speciosus (Koen.) & 2017 & Antimicrobiana & Al-Kattan et al., 2017 \\
\hline C. spiralis & $\begin{array}{l}\text { In vivo assessment of cyto/genotoxic, antigenotoxic and antifungal potential of Costus spiralis (Jacq.) Roscoe } \\
\text { leaves and stems }\end{array}$ & 2018 & Antimicrobiana & Sousa et al., 2018 \\
\hline C. speciosus & $\begin{array}{l}\text { Antimicrobial, antiquorum sensing, and antiproliferative activities of sesquiterpenes from Costus speciosus } \\
\text { rhizomes }\end{array}$ & 2019 & Antimicrobiana & Ibrahim et al., 2019 \\
\hline C. spicatus & $\begin{array}{l}\text { Structural and Phytochemical aspect from vegetative part of Costus spicatus (Jacq.) Sw (Costaceae) [Aspectos } \\
\text { Estruturais e Fitoquímicos de partes vegetativas de Costus spicatus (Jacq.) Sw. (Costaceae)] }\end{array}$ & 2013 & Fitoquímicas & Paes et al., 2013 \\
\hline C. speciosus & $\begin{array}{l}\text { Pharmacognostical study and establishment of quality parameters of aerial parts of Costus speciosus-a well known } \\
\text { tropical folklore medicine }\end{array}$ & 2014 & Fitoquímicas & Singh et al., 2014 \\
\hline C. arabicus & Aqueous extract of Costus arabicus inhibits calcium oxalate Crystal growth and adhesion to renal epithelial cells & 2015 & Urolítica & De Cógáin et al., 2015 \\
\hline C. spicatus & $\begin{array}{l}\text { Nephroprotective and antilithiatic activities of Costus spicatus (Jacq.) Sw.: Ethnopharmacological investigation of } \\
\text { a species from the Dourados region, Mato Grosso do Sul State, Brazil }\end{array}$ & 2021 & Urolítica & Moreno et al., 2021. \\
\hline
\end{tabular}




\subsection{Prospecção fitoquímica de diferentes extratos obtidos de Costus}

Nem todos os artigos inclusos nessa revisão realizou testes para prospecção fitoquímica. Alguns diferentes extratos obtidos de Costus speciosus, Costus spicatus, C. spiralis e Costus arabicus foram submetidos a ensaios para a detecção de diferentes classes de metabólitos. Na Tabela 2 observa-se que 18 classes foram pesquisadas no total, entretanto para maioria dos extratos o estudo se restringe a poucas classes de metabólitos secundários, sendo muito restrita a prospecção fitoquímica.

A prospecção fitoquímica visa detectar a presença de diferentes classes de metabólitos presentes no extrato, norteando as demais etapas do estudo químico. Neste método podem se utilizar testes de reações químicas ou por métodos cromatográficos (Soares, Santos, Vieira, Pimenta \& Araújo, 2016). A elevada composição química dos extratos obtidos de plantas desperta o interesse, pois vários compostos têm se mostrado ativos para o tratamento de diferentes enfermidades, bem como para o controle de pragas e podem possuir elevado valor nutricional (Cunha et al., 2014; Oliveira, Akisue, G. \& Akisue, M. 2014).

Os testes realizados com Costus speciosus, Costus spicatus, Costus spiralis e Costus arabicus não foram homogêneos, mas houve presença em comum dos seguintes compostos: Compostos fenólicos, Flavonoides, Saponinas, Taninos e Triterpenos. Reitera-se que a realização de estudos de prospecção fitoquímica detalhada, para cada espécie de Costus pode contribuir para o planejamento de métodos para realização do isolamento dos constituintes químicos, bem como, para nortear o planejamento de estudos que visem avaliar suas atividades biológicas e/ou toxicidade. 
Research, Society and Development, v. 10, n. 8, e4410816902, 2021

(CC BY 4.0) | ISSN 2525-3409 | DOI: http://dx.doi.org/10.33448/rsd-v10i8.16902

Tabela 2. Composição fitoquímica de Costus speciosus, Costus spicatus, Costus spiralis e Costus arabicus.

\begin{tabular}{|c|c|c|c|c|c|c|c|c|c|c|c|c|c|c|c|c|c|c|c|c|}
\hline \multirow{2}{*}{ Espécie } & \multirow{2}{*}{ Amostra } & \multicolumn{18}{|c|}{ Metabólito } & \multirow[b]{2}{*}{ Referência } \\
\hline & & 1 & 2 & 3 & 4 & 5 & 6 & 7 & 8 & 9 & 10 & 11 & 12 & 13 & 14 & 15 & 16 & 17 & 18 & \\
\hline \multirow{5}{*}{ C. speciosus } & EEPFCS & - & NT & - & - & NT & + & - & NT & NT & NT & + & NT & NT & + & - & - & NT & NT & Singh et al., 2014 \\
\hline & ECFCS & + & NT & - & + & NT & + & + & NT & NT & NT & + & NT & NT & - & + & + & NT & NT & \\
\hline & EEAFCS & + & NT & + & + & NT & - & + & NT & NT & NT & + & NT & NT & - & - & + & NT & NT & \\
\hline & EEFCS & + & NT & + & + & NT & - & + & NT & NT & NT & + & NT & NT & + & + & + & NT & NT & \\
\hline & EAFCS & - & NT & + & + & NT & - & + & NT & NT & NT & + & NT & NT & - & + & + & NT & NT & \\
\hline \multirow{6}{*}{ C. spicatus } & EARCS & - & + & NT & - & - & NT & NT & - & - & NT & NT & + & - & NT & + & - & NT & - & Paes et al., 2013 \\
\hline & EACCS & - & + & NT & - & - & NT & NT & - & - & NT & NT & + & - & NT & + & + & NT & - & \\
\hline & EAFCS $^{2}$ & - & + & NT & - & - & NT & NT & - & - & NT & NT & + & - & NT & + & + & NT & - & \\
\hline & EHERCS & - & - & NT & + & - & NT & NT & + & - & NT & NT & - & + & NT & + & - & NT & - & \\
\hline & EHECCS & + & - & NT & + & - & NT & NT & + & - & NT & NT & + & + & NT & + & - & NT & - & \\
\hline & EHEFCS & + & - & NT & + & + & NT & NT & + & - & NT & NT & - & - & NT & + & + & NT & - & \\
\hline \multirow{5}{*}{ C. spiralis } & EMFCS & NT & NT & NT & NT & NT & + & + & NT & NT & NT & NT & NT & NT & NT & + & + & + & NT & De Farias Silva et al., 2021 \\
\hline & ClFL & NT & NT & NT & NT & NT & + & - & NT & NT & NT & NT & NT & NT & NT & - & - & - & NT & \\
\hline & AcFL & NT & NT & NT & NT & NT & + & - & NT & NT & NT & NT & NT & NT & NT & - & - & - & NT & \\
\hline & EFL & NT & NT & NT & NT & NT & - & + & NT & NT & NT & NT & NT & NT & NT & + & + & - & NT & \\
\hline & MFL & NT & NT & NT & NT & NT & + & + & NT & NT & NT & NT & NT & NT & NT & - & - & + & NT & \\
\hline \multirow{2}{*}{ C. spiralis } & EACCS $^{2}$ & - & NT & NT & + & NT & NT & + & + & NT & + & NT & NT & NT & NT & + & + & NT & NT & Sousa et al., 2018 \\
\hline & EAFCS $^{3}$ & - & NT & NT & + & NT & NT & + & + & NT & + & NT & NT & NT & NT & + & + & NT & NT & \\
\hline \multirow{2}{*}{ C. arabicus } & EESC & + & NT & NT & + & + & - & + & - & - & + & NT & NT & + & NT & NT & - & + & + & Cunha et al., 2011 \\
\hline & EELC & + & NT & NT & - & + & - & + & - & + & + & NT & NT & + & NT & NT & + & + & + & \\
\hline
\end{tabular}

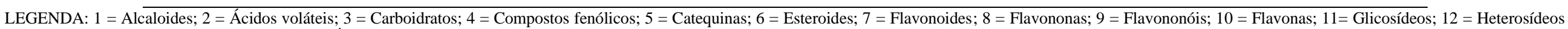

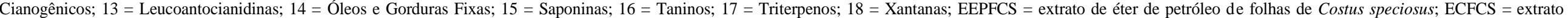

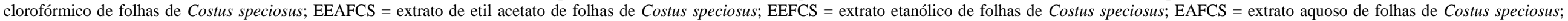

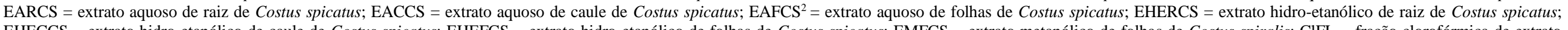

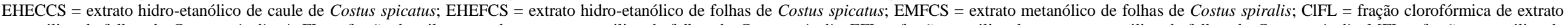

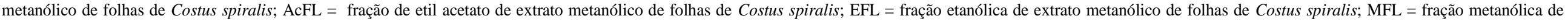

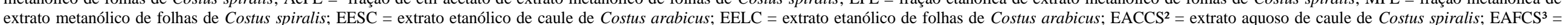

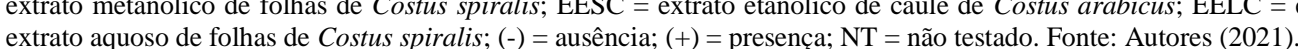




\subsection{Atividades farmacológicas avaliadas}

\subsubsection{Atividade anti-inflamatória}

Os artigos inclusos nessa revisão que realizaram testes acerca de atividade anti-inflamatória não trabalharam com todas as espécies que compõem o gênero Costus. Foram encontrados artigos que testaram extratos, frações e composto isolados somente das espécies: Costus afer, Costus speciosus, Costus spicatus, Costus spiralis e Costus igneus.

A fração hexânica de folhas de Costus afer (CAHLF) foi submetida a avaliação da atividade anti-inflamatória, utilizando diferentes modelos inclusive de artrite. Os resultados obtidos foram promissores e sugerem que esta fração possua elevado potencial para o tratamento da artrite (Tabela 3) (Anyasor et al., 2014; Anyasor et al., 2015). Ratos artríticos tratados com CAHLF tiveram uma redução significativa $(\mathrm{P}<0,05)$ níveis de malondialdeído (MDA) no cérebro, fígado e rim em comparação com o grupo de controle (Anyasor et al., 2014). Isso sugere que ratos artríticos tratados com CAHLF foram mais bem protegidos contra a insurgência proliferação de sinovite destrutiva (Maurice et al., 1997; Tak, Zvaifler, Green \& Firestein, 2000).

Em muitas articulações, doenças, os fatores pró-inflamatórios, como citocinas e prostaglandinas, juntamente com espécies reativas de oxigênio (ROS) e o óxido nítrico (NO) são liberados em locais de inflamação (Sakurai et al., 1995). Esses fatores são associados com atividade supeóxido dismutase (SOD) muito baixa durante a inflamação. Isso pode ser responsável pela redução da atividade de SOD no grupo de controle em comparação com os tratados com CAHLF grupos. A atividade da SOD é um componente chave do sistema antioxidante celular, protege as células e a matriz extracelular dos efeitos nocivos do ânion superóxido (O2•-) e os seus derivados, como o radical hidroxila $(\bullet \mathrm{OH})$ (Afonso, Champy, Mitrovic, Collin \& Lomri, 2007). SOD é conhecido por converter O2• - para H2O2 (Afonso et al., 2007). Catalase (CAT) é conhecido por desintoxicar o $\mathrm{H}_{2} \mathrm{O}_{2}$ gerado na água e oxigênio (Anyasor et al., 2014).

A elevação da atividade da CAT do tecido pode conferir proteção contra inflamação mediada por ROS nos grupos tratados com CAHLF, enquanto a redução do tecido CAT a atividade enzimática no grupo controle invariavelmente aumentaria o estresse oxidativo nos tecidos. Isso é porque o $\mathrm{H}_{2} \mathrm{O}_{2}$ gerado poderia ser convertido em $\mathrm{HOCl}$, agente inflamatório que pode reagir com $\mathrm{O} 2 \cdot$ - formar $\bullet \mathrm{OH}$, que pode reagir e danificar a uma taxa de difusão controlada em quase todas as moléculas em células vivas. Oxidação de proteínas, lipídios, DNA e polissacarídeos mostraram estar aumentados em pacientes com artrite reumatóide (Hitchon \& Ei-Gabalawy, 2004). A glutationa S-transferase (GST) catalisa a reação inicial envolvendo a conjugação de constituinte eletrofílico reativo com glutationa reduzida (GSH) removendo assim proteger as macromoléculas do tecido do efeito deletério da peroxidação lipídica mediada por ROS (Egwunyenga, Isamah \& Nmorsi, 2004).

De Costus speciosus foram isoladas as seguintes sesquiterpenolactona: 22,23-dihydrospinas-terone (1), dehydrodihydrocostus lactone (mokko lactone) (2), dehydrocostus lactone (3), stigmasterol (4), arbusculin A (5), santamarine (douglanin) (6), reynosin (7) e specioic acid (8). Todos foram submetidos a avaliação da atividade sobre IL1 $\beta$, IL-6, TNF $\alpha$, PGE2 e Lipoxigenase. Os compostos de 1 a 4 reduziram os níveis de IL-6 e TNF $\alpha$. Todos os compostos reduziram os níveis de IL-1 $\beta$ e PGE2 e as substâncias 5 e 6 apresentaram melhor efeito inibitório sobre a COX-2 e Lipoxigenase (Tabela 3) (AlAttas et al., 2015).

Geralmente, as citocinas podem ser categorizadas como pró-inflamatórias ou anti-inflamatórias, dependendo de seus papéis na inflamação (Hopkins, 2003). Citocinas pró-inflamatórias, como IL-1 $\beta$, IL-6 e TNF- $\alpha$ estão envolvidas em a iniciação e amplificação da inflamação, enquanto as citocinas anti-inflamatórias (por exemplo, IL-10 e TGF- $\beta$ ) modulam negativamente esses eventos (Dinarello, 2000; Opal \& DePalo, 2000). Tem sido mostraram que as citocinas pró-inflamatórias agem por ativação de fatores de transcrição (por exemplo, NF-אB e AP-1) e proteínas quinases (MAPK e PKC). Por sua vez, a expressão de muitos genes-alvo é aumentada para manter o estado inflamatório. Por exemplo, as citocinas podem ser responsáveis pela indução de várias enzimas (por exemplo, iNOS e COX-2) que são cruciais para iniciar e manter o processo inflamatório 
processo (Kracht \& Saklatvala, 2002). As lactonas sesquiterpênicas testadas causaram uma diminuição das citocinas proinflamatórias (IL-1 $\beta$, IL-6 e TNF- $\alpha$ ) com diminuição do nível das enzimas alvo (COX-2 e lipoxgenase-5) e subsequente redução de seu produto inflamatório (PGE2) de forma dose-dependente (Al-Attas et al., 2015).

Outro estudo avaliou a atividade antinociceptivo (analgésico) do extrato metanólico obtido das folhas de Costus spicatus (MECs), apresentou significativo efeito antinociceptivo e parece que esta atividade tem relação com sua atividade anti-inflamatória (Tabela 3). Todos os resultados obtidos sugerem que o MECs possui propriedades analgésicas e antiinflamatórias, provavelmente mediadas pela inibição da síntese de prostaglandinas e pela inibição central mecanismos (Quintans-Junior et al., 2010). Outro extrato aquoso de folhas de Costus spicatus (CSE) apresentou atividades antiinflamatório e antinociceptivo (Tabela 3) (Picanço et al., 2016). Estudos químicos levaram ao isolamento de três polissacarídeos neutros com atividade anti-inflamatório e atividades imunomoduladoras (da Silva \& Parente, 2003).

As amostras ClFL, AcFL, EFL e MFL obtidas de Costus spiralis também mostraram efeito anti-inflamatório promissor da espécie (Tabela 3) (De Farias Silva et al., 2021). O ácido acético inoculado induz irritação na membrana peritoneal mediada por macrófagos e mastócitos, liberando mediadores inflamatórios como TNF- $\alpha$, IL-1 $\beta$, IL-8 e PGs. Estes mediadores, juntamente a outros simpatomiméticos induzem hiperalgesia, desencadeando reações motoras de contração/rotação abdominal e extensão de membros (Ribeiro et al., 2000). Nesse sentido, as amostras ClFL, AcFL e EFL confirmam suas ações moduladores nestes mediadores inflamatórios, uma vez que inibiram significativamente as contorções. No teste de peritonite induzida por Zymosan A, também foi descrito ação significativa das amostras ClFL, AcFL, EFL e MFL na, comparados a droga de referência indometacina corroborando a atividade de modulação dos mediadores inflamatórios TNF- $\alpha$, IL-1 $\beta$, IL-8 e PGs (De Farias Silva et al., 2021; Ribeiro et al., 2000).

No teste de formalina em ratos, a injeção intraplantar de formalina (solução de formaldeído a 1\%) na pata induz uma resposta dividida em duas fases: uma fase curta que pode ser devido à estimulação química direta dos nociceptores, enquanto a segunda fase é dependente de mecanismos periféricos (Le Bars, Gozariu \& Cadden, 2001). Durante o estágio neurogênico (0-5 min), as amostras não reduziram significativamente o tempo de lambida da pata. No estágio inflamatório (15-30 min), AcFL, EFL e MFL reduziram, porém ClFL não mostrou tempo significativo. Sendo assim, as frações AcFL, EFL e MFL possuem efeito antinociceptivo comparado a AINEs (De Farias Silva et al., 2021; Le Bars et al., 2001). Assim como no estudo de Anyasor et al (2014; 2015), de Farias Silva et al (2021) utilizou o mesmo modelo para avaliar a atividade anti-inflamatória em ratos artríticos e obtendo resultados semelhantes, porém após experimentar as amostras ClFL e MFL. ClFL diminuíram o edema da pata (a partir do $21^{\circ}$ dia) após o estímulo com CFA, mas o mesmo resultado não foi observado em animais tratados com MFL.

Semelhante as demais espécies, extrato, frações e substância isolada de Costus igneus também apresentaram atividade anti-inflamatória e analgésica. MEC foi fracionado obtendo-se CEC, HEC, EtEC e BEC que foram submetidos aos testes de edema de pata, sendo que o CEC exibiu inibição significativa no edema de pata induzido por carragenina, enquanto HEC, EtEC e BEC mostrou efeitos anti-edematogênicos menores (Krishnan et al., 2014). Esses resultados sugerem que os extratos atuam nos metabólitos do ácido araquidônico, que produzem um edema dependente da mobilização de neutrófilos (Just et al., 1998). As atividades das enzimas COX, 5-LOX e 15-LOX em células mononucleares de rato foram significativamente maiores nos ratos induzidos por carragenina, indicando o aumento da produção de prostaglandinas (PGs) e leucotrieno (LT), sendo que o tratamento com MEC reduziu significativamente as atividades dessas enzimas (Krishnan et al., 2014).

O tratamento com MEC diminuiu a infiltração de neutrófilos causada pela indução de carragenina. A atividade da enzima óxido nítrico sintase que gera NO, que é um vasodilatador potente e contribui para a formação de edema na inflamação aguda, foi significativamente maior nos ratos induzidos por carragenina, enquanto a atividade diminuiu significativamente nos 


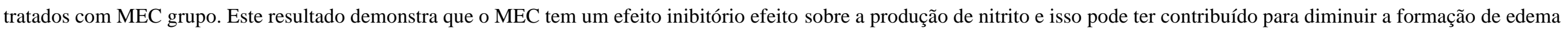
(Krishnan et al., 2014).

Tabela 3. Atividade anti-inflamatória e analgésicos de Costus afer, Costus speciosus, Costus spicatus, Costus spiralis e Costus igneus.

\begin{tabular}{|c|c|c|c|}
\hline Espécie & Amostra & Modelo & Resultados obtidos \\
\hline \multirow{3}{*}{ C. afer ${ }^{1}$} & \multirow{3}{*}{ CAHLF } & $\begin{array}{l}\text { Edema de pata induzido por } \\
\text { carragenina em ratos } \\
\text { Inflamação induzida pelo ácido } \\
\text { araquidônico em ratos }\end{array}$ & $\begin{array}{l}\text { Via oral em doses de } 100,250 \text { e } 500 \mathrm{mg} / \mathrm{kg} \text { suprimiu }(\mathrm{P}<0,05) \text { o edema (dose-dependente) comparado } \\
\text { ao grupo de controle, ligeiramente após } 1 \mathrm{~h} \text { e apreciavelmente após a } 2^{\mathrm{a}} \mathrm{h} \text {. } \\
\text { Via oral em doses de } 50-250 \mathrm{mg} / \mathrm{kg} \text { suprimiu significativamente }(\mathrm{P}<0,05) \text { o edema quando } \\
\text { comparado com o grupo de controle. }\end{array}$ \\
\hline & & $\begin{array}{l}\text { Artrite induzida por formaldeído em } \\
\text { ratos }\end{array}$ & $\begin{array}{l}\text { Via oral em doses de } 50-250 \mathrm{mg} / \mathrm{kg} \text { em ratos induzidos com artrite reduziu significativamente }(\mathrm{P} \\
<0,05) \text { a espessura do edema da pata comparado ao grupo de controle, onde o grupo tratado com a } \\
\text { maior dose suprimiu a espessura do edema da pata a partir do } 2^{\circ} \text { dia ao } 7^{\circ} \text { dia, enquanto os outros } \\
\text { grupos de tratamento mostraram do } 3^{\circ} \text { dia ao } 7^{\circ} \text { dia. }\end{array}$ \\
\hline & & Artrite induzida por CFA em ratos & $\begin{array}{l}\text { Via oral em doses de } 50-250 \mathrm{mg} / \mathrm{kg} \text { para os grupos infectados com CFA teve uma espessura da pata } \\
\text { significativamente }(\mathrm{P}<0,05) \text { reduzida em comparação com o grupo de controle }\end{array}$ \\
\hline C. afer $^{2}$ & CAHLF & $\begin{array}{l}\text { Artrite induzida por formaldeído em } \\
\text { rato }\end{array}$ & $\begin{array}{l}\text { Os ratos tratados com 50, } 100 \text { e } 250 \mathrm{mg} / \mathrm{kg} \text { reduziram significativamente }(\mathrm{p}<0,05) \text { o } \mathrm{HC}, \mathrm{WBC}, \mathrm{LC} \text {, } \\
\mathrm{NC}, \mathrm{BEMC} \text { e PC em comparação ao grupo de controle } \\
\mathrm{O} \text { grupo tratado com } 50,100 \text { e } 250 \mathrm{mg} / \mathrm{kg} \text { reduziu significativamente }(\mathrm{p}<0,05) \text { o } \mathrm{HC}, \mathrm{WBC}, \mathrm{LC}, \mathrm{NC} \text {, } \\
\text { BEMC e PC em comparação ao grupo de controle }\end{array}$ \\
\hline \multirow{4}{*}{ C.speciosus ${ }^{3}$} & $\begin{array}{l}\text { 22,23-dihydrospinas- } \\
\text { terone } \quad(1) \\
\text { dehydrodihydrocostus }\end{array}$ & Avaliação do nível de IL-1 $\beta$ & 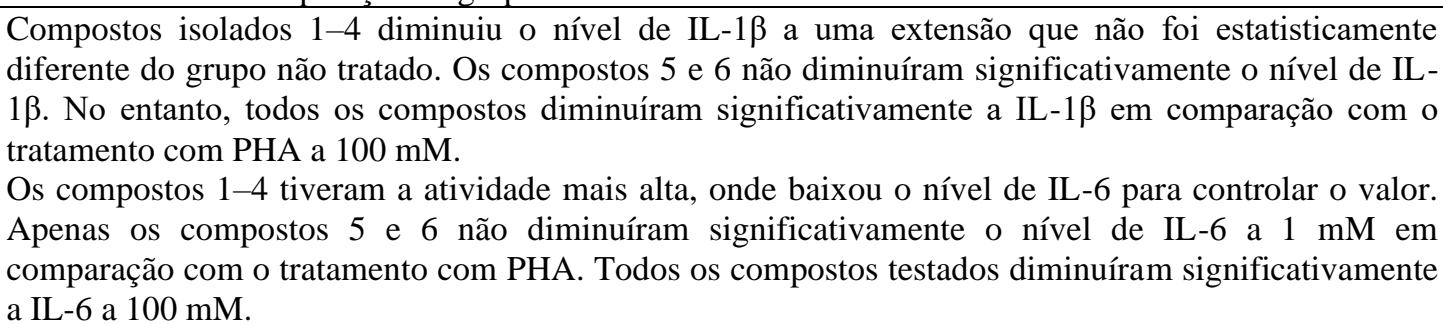 \\
\hline & $\begin{array}{ll}\begin{array}{ll}\text { lactone } & (3), \\
\text { stigmasterol } & (4), \\
\text { arbusculin } & \text { A } \\
\text { santamarine } \\
\text { (douglanin) }\end{array} & (6),\end{array}$ & Avaliação do nível de TNF- $\alpha$ & $\begin{array}{l}\text { Os compostos } 1-4 \text { a } 100 \mathrm{mM} \text { reduziram o nível de TNF- } \alpha \text { a ponto de não haver diferença estatística } \\
\text { em relação ao grupo de controle. As amostras testadas a } 10 \mathrm{mM} \text { causaram uma diminuição relacionada } \\
\text { à concentração no nível de TNF- } \alpha \text {, mas não conseguiram atingir os valores de controle. Os compostos } \\
5 \text { e } 7 \text { não diminuíram significativamente o nível de TNF- } \alpha \text { em } 1 \mathrm{mM} \text { quando comparados ao grupo } \\
\text { tratado com PHA. }\end{array}$ \\
\hline & $\begin{array}{l}\text { reynosin }(7) \\
\text { specioic acid (8) }\end{array}$ & Avaliação do nível de PGE2 & $\begin{array}{l}\text { A maioria dos compostos a } 100 \mathrm{mM} \text { diminuiu significativamente os níveis de PGE2 do grupo tratado } \\
\text { com PHA sem qualquer diferença estatística do grupo não tratado, exceto } 5 \text { e } 6 \text {. }\end{array}$ \\
\hline & & $\begin{array}{l}\text { Avaliação do nível de lipoxgenase-5 } \\
\text { Avaliação do nível de COX-2 }\end{array}$ & $\begin{array}{l}\text { Os compostos 1-4 reduziram os níveis de COX-2 e lipoxgenase-5 a um ponto que não foi } \\
\text { estatisticamente diferente do grupo de controle. Os compostos } 5 \text { e } 6 \text { não diminuíram }\end{array}$ \\
\hline
\end{tabular}


C.spicatus $^{4} \quad$ MECs

C.spicatus $^{5} \quad$ CSE

ClFL;AcF;

MFL

significativamente os níveis de COX-2 e lipoxgenase-5 a $1 \mathrm{mM}$, em comparação com o tratamento com PHA. No entanto, todos os compostos diminuíram os níveis de COX-2 e lipoxgenase-5 na concentração de $100 \mathrm{mM}$ em comparação com o tratamento com PHA.

Contorções induzidas por ácido acético em camundongos

Dor induzida por formalina em camundongos

Teste de placa quente com Doses de 200 e $400 \mathrm{mg} / \mathrm{kg}$ causaram um aumento significativo na latência de resposta do teste da camundongc

Teste Rota-Rod com camundongos

Teste de edema induzido por carragenina em camundongos

Indução de edema de pata em Reduziu significativamente o edema em todas as concentrações testadas $(1,25 ; 2,5 ; 5,0 ; 7,5$ e 10 camundongos

Teste de formalina em ratos

Peritonite induzida por veneno de B. atrox em camundongos

Atividade coagulante no plasma

humano

Atividade hemorrágica em ratos

Método hemolítico indireto

Contorções abdominais induzidas por ácido acético em ratos

Teste de formalina em ratos

Teste de placa quente com ratos

Teste de peritonite induzida por Zymosan A em ratos

Artrite induzida por CFA em ratos

Em todas as doses, foi capaz de inibir as contorções induzidas por ácido acético em camundongos.

Efeitos analgésicos na primeira $(0-5 \mathrm{~min})$ e na segunda fase $(15-30 \mathrm{~min})$ da dor induzida por formalina, onde todas as doses bloquearam significativamente a dor inflamatória.

placa quente quando comparados aos animais do grupo controle.

Os camundongos não apresentaram alterações significativas no desempenho motor com doses de 100, 200 ou $400 \mathrm{mg} / \mathrm{kg}$

Doses de 200 e 400mg/kg (i.p.) exibiu efeito anti-inflamatório, com interferência na síntese do mediador inflamatório.

$\mathrm{mg} / \mathrm{kg} / 25 \mathrm{~mL}$ PBS) quando comparado com BAV sozinho

Demonstrou o efeito analgésico na primeira (0-5 min) e na segunda fases (20-30 min) da dor induzida por BAV, onde na segunda fase as concentrações mais baixas exibiram potencial analgésico ligeiramente superior.

Diminuiu significativamente o número de leucócitos nas três concentrações mais baixas, indicando efeito na migração de células inflamatórias induzida pela administração de BAV.

As concentrações não inibiram a atividade coagulante de BAV.

Não inibiu significativamente a hemorragia induzida por BAV.

Não inibiu a atividade de PLA2 de BAV.

A administração de ClFL, AcFL e EFL inibiu significativamente as contorções em 73,5 \pm 8,4\% (p

$<0,001$ ), 56,7 $\pm 8,9 \%$ ( $p<0,001$ ) e $61,1 \pm 3,6 \%$ ( $<<0,001$ ), respectivamente, em relação aos controles.

MFL não mostrou inibição significativa em $6,3 \pm 3,0 \%$, em relação aos controles.

Durante o estágio neurogênico (0-5 min), as amostras não reduziram significativamente o tempo de lambida da pata. No estágio inflamatório (15-30 $\mathrm{min})$, AcFL, EFL e MFL reduziram significativamente o tempo de lambida da pata em 69,6 $\pm 11,9 \%(\mathrm{p}<0,001), 58,2 \pm 9,4 \%(\mathrm{p}<0,01)$ e $79,6 \pm 8,3 \%$ (p <0,001), respectivamente. Em 32,7 $\pm 21,3 \%$, ClFL não mostrou tempo significativamente reduzido de lambida da pata.

Não reduziu significativamente a latência de reação do estímulo térmico.

Migração celular foi significativamente reduzida em animais tratados com droga de referência $(67,2 \pm$ $3,0 \% ; \mathrm{p}<0,001)$, ClFL $(61,8 \pm 11,4 \% ; \mathrm{p}<0,001)$, AcFL $(58,7 \pm 8,3 \% ; \mathrm{p}<0,001)$, EFL $(39,2 \pm 5,0 \%$; $\mathrm{p}<0,001)$ e MFL $(64,8 \pm 4,4 \% ; \mathrm{p}<0,001)$

Tanto a droga padrão $\left(16^{\circ}-21^{\circ}\right.$ dias) quanto o ClFL diminuíram o edema da pata (a partir do $21^{\circ}$ dia) após o estímulo com CFA. O mesmo não foi observado em animais tratados com MFL. 
Edema de pata induzido por Diminuição significativa no edema foi observada de uma maneira dependente da dose e $100 \mu \mathrm{g}$ carragenina em ratos

induzidos por LPS

Translocação de NF-kB induzida por As células tratadas com b-amyrin inibiram significativamente a ativação de NF-kB de uma maneira LPS em hPBMCs

Edema de pata induzido por

carragenina em ratos

Atividade da ciclooxigenase (COX) e

das lipoxigenases (5-LOX e 15-LOX)

em células

Atividade da mieloperoxidase (MPO)

do óxido nítrico sintase (NOS) no

tecido da pata

Edema de pata induzido por Dose de $50 \mathrm{mg} / \mathrm{kg}$ de peso corporal, CEC exibiu inibição significativa no edema de pata induzido por carragenina em ratos

CEC

Inibição de COX-2, mieloperoxidase

(MPO) e óxido nítrico sintase (NOS)

no tecido da pata

AEC; EEC; HEC; Edema de pata induzido por EtEC; BEC carragenina em ratos

dependente da concentração

Exerceu inibição do edema de 69 e $80 \%$ em 3 e 5 h, respectivamente.

O pré-tratamento de MEC diminuiu significativamente a atividade COX. A atividade de 15-LOX e 5LOX diminuíram significativamente em ratos tratados com $100 \mathrm{mg} / \mathrm{kg}$ de MEC

$100 \mathrm{mg} / \mathrm{kg}$ diminuiu significativamente a atividade de MPO e NOS

carragenina em 47 e $63 \%$ em 3 e $5 \mathrm{~h}$.

$\mathrm{O}$ tecido da pata de ratos administrados com $50 \mathrm{mg} / \mathrm{kg}$ exerceu um efeito inibitório significativo de $70 \%$ na atividade COX-2 e o restante é a atividade COX-1 (30\%), também diminuiu significativamente a atividade de MPO quando comparado com ratos induzidos por carragenina. A CEC exerceu efeito inibitório significativo sobre a atividade da NOS em relação ao controle da carragenina.

AEC e EEC tiveram um efeito inibitório de 43 e $50 \%$ em 3 he 65 e $69 \%$ em 5 h, respectivamente. inibitório de 50, 60 e $48 \%$ foi observado em 5 horas

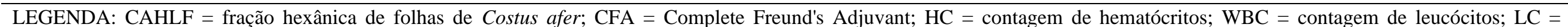

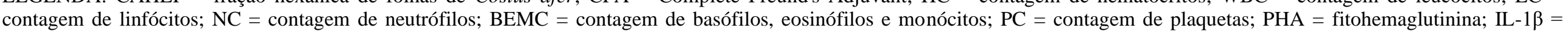

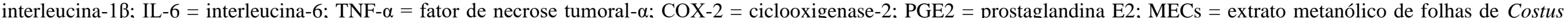

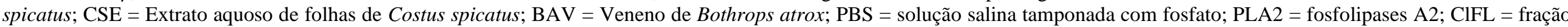

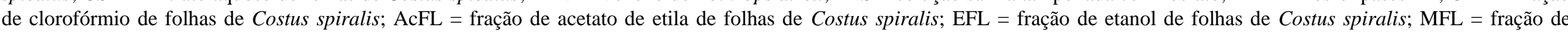

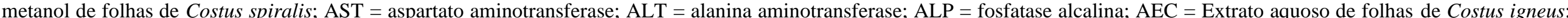

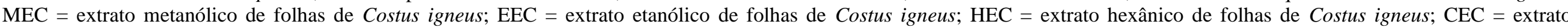

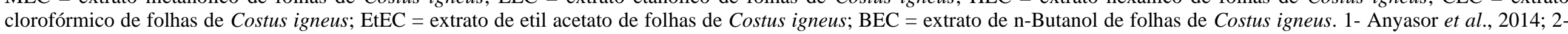

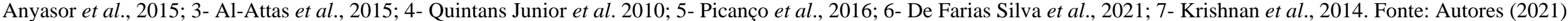




\subsubsection{Atividades antidiabética e urolítica}

Em estudo foi avaliada a atividade antioxidante da costunolida e eremanthin em vários órgãos como cérebro, pâncreas, fígado, coração e rins que foram danificados pelo estresse oxidativo devido ao diabetes induzido pela estreptozotocina. A diabetes mellitus induzida por injeção única intraperitoneal de STZ em ratos machos, sendo estabilizada nestes ratos ao longo de um período de 7 dias. Os animais de controle foram tratados com tampão citrato (pH-4.5). Após 7 dias, o sangue foi coletado por punção sinocular e o nível de glicose plasmática de cada rato foi determinado. Ratos com uma faixa de glicose plasmática em jejum de $280-350 \mathrm{mg} / \mathrm{dl}$ foram considerados diabéticos e incluídos no estudo (Tabela 4) (Eliza et al., 2010).

Os resultados obtidos após tratamento diário com costunolide e eremanthin para ratos diabéticos induzidos por STZ mostram aumento da magreza (SOD, CAT e GPx). Esses resultados retratam o mecanismo de proteção do costunolida e do eremanthin, reduzindo o dano oxidativo e fortalecendo o pool de antioxidantes enzimáticos e não enzimáticos na célula. Podese assim afirmar que o tratamento de ratos diabéticos induzidos por STZ com costunolida e eremanthin isolados de Costus speciosus amenizou as condições de estresse oxidativo, indicando a natureza protetora desses compostos (Tabela 4) (Eliza $e t$ al., 2010). Nesse sentido, os efeitos antioxidantes do costunolida e do eremanthin reflete sua contribuição no equilíbrio homeostático de oxidantes em células e tecidos, podendo atuar de forma preventiva ou ajudando na terapia de doenças decorrentes de tal desequilíbrio antioxidante, como a diabetes (Barbosa, 2010).

Em outro estudo o extrato etanólico das raízes de Costus speciosus foi testado quanto a efeitos na expressão gênica e atividades de enzimas glicolíticas. Sessenta ratos albinos machos ( $120 \pm 20 \mathrm{~g}$ de peso e 6 meses de idade) foram utilizados e divididos em 6 grupos $(\mathrm{n}=10)$. Dois grupos serviram como controles diabéticos e não diabéticos. Quatro grupos de animais diabéticos-STZ receberam Costus speciosus oral (CSREt) em doses de 200, 400 e $600 \mathrm{mg} / \mathrm{kg}$ de peso corporal e $600 \mu \mathrm{g} / \mathrm{kg}$ de peso corporal da droga padrão glibenclamida por 4 semanas. O efeito anti-hiperglicêmico de CSREt foi dependente da dose e seu efeito hipoglicêmico se deve a presença de eremanthin (substância ativa de Costus speciosus), exercido por meio da potencialização da síntese e liberação de insulina das células beta existentes, além de aumentar a sensibilidade da insulina aos tecidos à captação de glicose. (Tabela 4) (Ali et al., 2014).

O diabete tipo 2 é uma doença que se caracteriza por diminuição da secreção pancreática de insulina e uma diminuição da ação da insulina ou resistência à insulina nos 5 órgãos periféricos, resultando em hiperglicemia e glicotoxicidade: responsável por um estresse oxidativo crônico no tecido, originando complicações crônicas do diabete. A resistência à insulina é inicialmente observada no tecido muscular, onde concentração crescente de insulina é necessária para permitir a captação de glicose pelo miócito (Marcondes, 2007). Nesse sentido, CSREt se mostra relevante, uma vez que melhorou a atividade e a expressão gênica de receptores de insulina A (IRA) e das enzimas catabólicas da glicose hepática como glucoquinase (GK), aldolase, piruvato quinase (PK) e succinato desidrogenase (SDH) em harmonia, aumentando o nível de expressão gênica do gene da insulina e os níveis séricos de insulina, contribuindo no equilíbrio glicêmico de ratos diabéticos, com potencial preventivo da glicotoxicidade acerca de prevenir complicações crônicas advindas da diabetes (Ali $e t$ al., 2014; Marcondes, 2007).

Outro estudo utilizou extrato metanólico de folhas de Costus speciosus (COS) para avaliar efeitos inibitórios nas atividades enzimáticas que foram medidas usando $\alpha$-amilase pancreática suína e $\alpha$-glucosidase de Saccharomyces cerevisiae. A atividade inibitória da $\alpha$-glucosidase foi detectada com um $\mathrm{CI}_{50}$ de $67,5 \mu \mathrm{g} / \mathrm{L}$, que foi significativamente menor do que o valor de $\mathrm{CI}_{50}$ da Acarbose ( $\mathrm{p}<0,01$ ), medicamento padrão. Os efeitos inibitórios da $\alpha$-amilase ocorreram em uma concentração comparativamente maior de extrato com um $\mathrm{CI}_{50}$ de $5,88 \mathrm{mg} / \mathrm{mL}$ que foi significativamente maior do que o valor de $\mathrm{CI}_{50}$ da Acarbose $(\mathrm{p}<0,01)$. COS $(250 \mu \mathrm{g} / \mathrm{mL})$ demonstrou efeitos inibitórios sobre a formação de frutosamina e a reticulação de proteína induzida por glicação que estavam em paridade com $1 \mathrm{mg} / \mathrm{mL}$ de aminoguanidina foram detectados. Essas 
descobertas fornecem evidências científicas para apoiar o uso de Costus speciosus para efeitos hipoglicêmicos com uma vantagem adicional em desacelerar a glicação de proteínas (Tabela 4) (Perera et al., 2015).

A $\alpha$-glicosidase e a $\alpha$-amilase são enzimas responsáveis pelo processamento de carboidratos complexos, glicoproteínas e glicolipídeos. Sendo assim, os efeitos inibitórios da $\alpha$-glicosidase e da $\alpha$-amilase contribuem para o controle glicêmico pós-brandial, confirmando a relevância dos extratos testados (Rosak, 2002; Seo et al., 2005). Além disso, nesse estudo foi demonstrado a ação de desaceleração na glicação de proteínas. Os produtos da glicação avançada, como a frutosamina, são capazes de modificar irreversivelmente, as propriedades químicas e funcionais das mais diversas estruturas biológicas podendo ser os principais responsáveis pelas complicações em pacientes diabéticos (Barbosa, 2008). Nesse sentido, sugere-se que folhas de Costus speciosus possa contribuir na prevenção de complicações diabéticas advindas de produtos de proteínas glicadas (Perera et al., 2015).

As folhas de Costus spiralis também foram testadas quanto a avaliação a atividade inibitória de $\alpha$-glucosidase (AGI) de extratos e compostos deles isolados. Frações de hexano, acetato de etila, metanol e frações aquosas foram obtidas por partição de um extrato de metanol bruto de folhas secas de revelou que a atividade AGI estava confinada à fração de acetato de etila. A purificação desta fração produziu schaftoside e isoschaftoside. As atividades AGI das duas flavonas foram menores do que a fração de acetato de etila, mas comparáveis com a do fármaco antidiabético acarbose. $\mathrm{O}$ valor de $\mathrm{CI}_{50}$ da fração de acetato de etila foi 1,95-, 2,34- e 2,22 vezes maior do que aqueles da acarbose, schaftoside e isoschaftoside, respectivamente.

Os flavonoides são responsáveis por inúmeras funções nas plantas e possui características muito importantes quanto a suas propriedades farmacológicas (Dos Santos \& Farias Rodrigues, 2017). A ingestão de flavonoides, tanto em sua forma isolada, quanto contidos em extratos de plantas ou frutas influencia a absorção dos carboidratos ingeridos, exercendo efeito hipoglicemiante por aumentar a sensibilidade a insulina e/ou inibidor da absorção intestinal de glicose em humanos e em ratos saudáveis e portadores de diabetes tipo II (Valle, 2016). Os resultados demonstram pela primeira vez que o schaftoside e o isoschaftoside são responsáveis, em parte, pela atividade AGI de Costus spiralis. e suportam a hipótese original de que Costus spiralis exibe propriedades anti-hiperglicêmicas resultantes da atividade AGI conferida pela presença de flavonoides (Tabela 4) (De Oliveira et al.,2018).

O estudo com extrato das folhas de Costus pictus (CPE) avaliou efeitos na função das células L e na secreção de Peptídeo semelhante ao glucagon (GLP-1), usando o modelo de células L de GLUTag murino estabelecido e buscou investigar seus potenciais efeitos citoprotetores contra os efeitos prejudiciais do palmitato e citocinas em células $\beta$ pancreáticas usando células BRIN-BD11 (Patibandla et al.,2020). A capacidade das células L de secretar GLP-1 em resposta direta aos nutrientes intestinais luminais pode ser o principal mecanismo de secreção de GLP-1. O peptídeo-1 semelhante ao glucagon (GLP-1) é um hormônio multifacetado com amplo potencial farmacológico que atua na estimulação da secreção de insulina dependente da glicose, diminuição do esvaziamento gástrico, inibição da ingestão de alimentos, aumento da natriurese e diurese e modulação da proliferação de células $\beta$ de roedores (Müller et al., 2019).

O CPE aumentou significativamente a porcentagem de células viáveis BRIN-BD11 e GLUTag e protegeu as células BRIN-BD11 contra a toxicidade induzida por palmitato e citocinas pró-inflamatórias. O CPE aumentou a secreção aguda de GLP-1 por 6,4-16,3 vezes das células GLUTag em concentrações baixas $(1,1 \mathrm{mM})$ e altas $(16,7 \mathrm{mM})$ de glicose $(\mathrm{P}<0,01)$. Tal resultado considera-se promissor quanto a utilização de CPE em situação de diabetes, uma vez que o GLP-1 possui ação anorexigênica e insulinotrópica (Müller et al., 2019). A expressão do gene antioxidante (Nrf2, Cat \& Gpx1) e pró-proliferativa (Erk1 e Jnk1) foi regulada positivamente por cultura de 24h com CPE, enquanto o fator de transcrição pró-inflamatório NF- $\mathrm{kB}$ foi regulado negativamente. Em conclusão, o CPE estimula agudamente a secreção de GLP-1 a partir de células L GLUTag, e isso pode ser parcialmente responsável por suas propriedades antidiabéticas (Tabela 4) (Patibandla et al.,2020). 
Espécies de do gênero Costus, como a Costus arabicus, também são utilizadas na medicina popular de algumas regiões do Brasil como parte para o tratamento de nefrolitíase, conhecida popularmente como pedra nos rins. Um estudo teve como objetivo avaliar extrato aquoso de Costus arabicus (EACA) quanto a inibição de crescimento de cristais de oxalato de cálcio e adesão às células epiteliais renais (De Cógáin et al., 2015). Geralmente o tratamento adequado da nefrolitíase pode ser dividido em três partes: tratamento da cólica renal, tratamento do cálculo e terapêutica da doença litiásica (Riella, 2003). Sendo assim, EACA mostra-se promissor quanto a seu uso para situações de nefrolitíase, uma vez que a EACA pode interromper a calculogênese ao interagir com as superfícies de cristal de CaOx. (Tabela 5) (De Cógáin et al., 2015).

Outro estudo avaliou os efeitos nefroprotetores da fração solúvel em etanol de Costus spicatus (ESCS) em um modelo de lesão renal aguda (LRA) em ratos Wistar e induziu a precipitação de oxalato de cálcio por oxalato de sódio em amostras de urina. Doses diferentes de ESCS (30, 100 e $300 \mathrm{mg} / \mathrm{kg}$ ) foram administradas por via oral por 5 dias. Os parâmetros urinários foram medidos nos dias 1, 3, 5 e 7. A precipitação do oxalato de cálcio foi induzida em amostras de urina com ESCS a 0,05, 0,5 e $5 \mathrm{mg} / \mathrm{mL}$ (Tabela 5) (Moreno et al., 2021).

Usando um modelo de LRA induzida por rabdomiólise em ratos, ESCS mitigou significativamente o dano renal induzido por lesão renal aguda. Quanto aos cristais, diminuiu significativamente a precipitação de cristais na urina de participantes saudáveis de forma dependente da dose na formação e nas áreas médias dos cristais. Além disso, a ESCS modificou a proporção dos dois tipos de cristais. Esses resultados são promissores uma vez que sugerem que ESCS inibe a formação e reduz a agregação de cristais, reduzindo diretamente a formação de cálculos renais. Porém, a possibilidade de que tais efeitos sejam totalmente reproduzidos em organismos vivos complexos ainda é especulativa, uma vez que os cálculos renais são formados na urina recém-produzida, mas não anula os resultados de que ESCS tem importantes efeitos preventivos contra esta condição (Tabela 5) (Moreno et al., 2021). 
Tabela 4. Atividade antidiabética de Costus speciosus, Costus spiralis e Costus pictus.

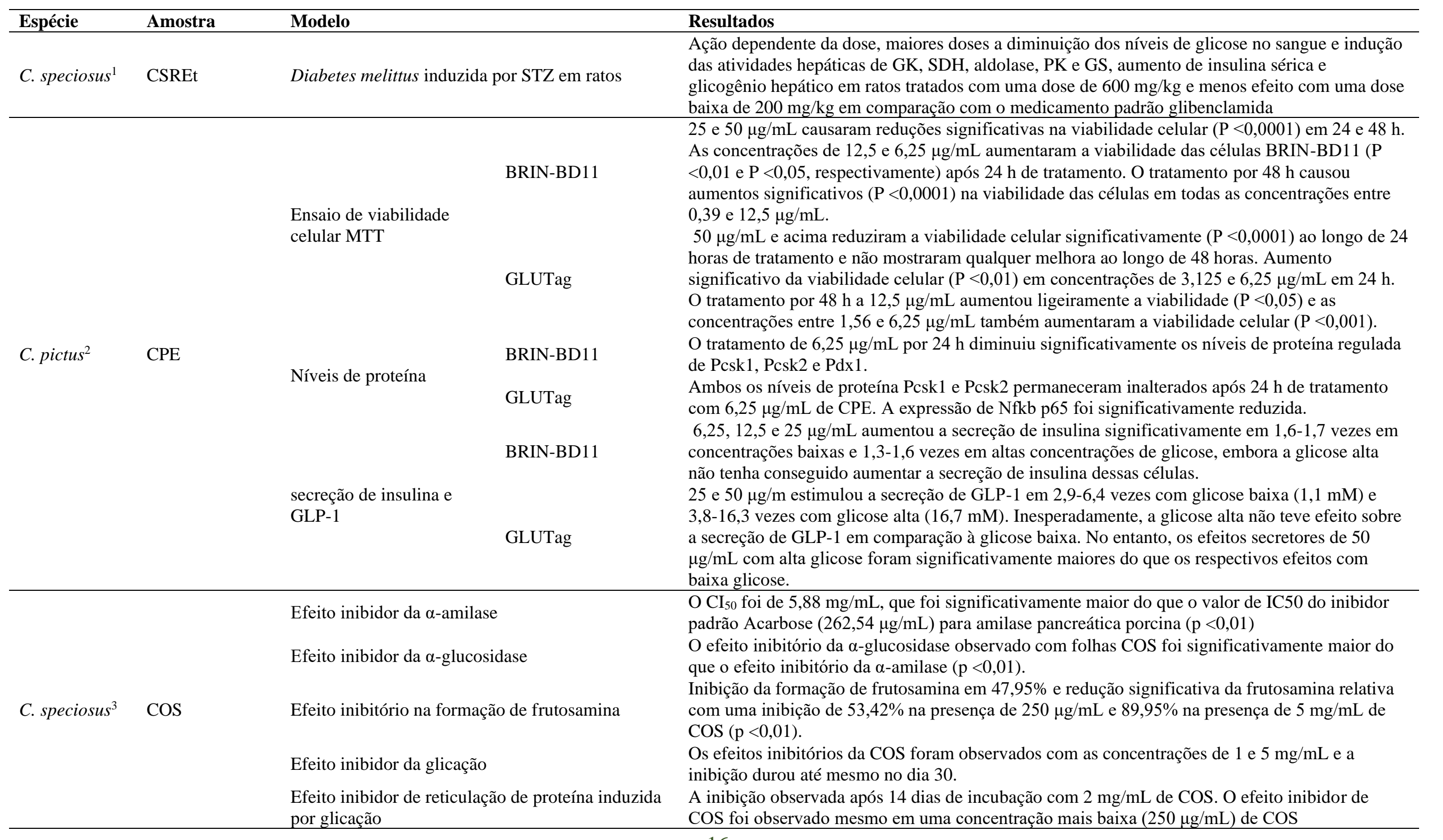




\begin{tabular}{|c|c|c|c|}
\hline \multirow{3}{*}{ C. spiralis $^{4}$} & \multirow{3}{*}{$\begin{array}{l}\text { EAECS } \\
\text { Schaftoside } 1 \\
\text { Isoschaftoside } 2\end{array}$} & \multirow{3}{*}{ Atividade inibidora de a-glicosidase } & $\mathrm{CI}_{50}=408,40 \mathrm{mg} / \mathrm{mL}$ \\
\hline & & & $\mathrm{CI}_{50}=954,12 \mathrm{mg} / \mathrm{mL}$ \\
\hline & & & $\mathrm{CI}_{50}=910,50 \mathrm{mg} / \mathrm{mL}$ \\
\hline \multirow{4}{*}{ C. speciosus $^{5}$} & \multirow{4}{*}{$\begin{array}{l}\text { Costunolide; } \\
\text { eremanthin }\end{array}$} & glicose plasmática em ratos & $\begin{array}{l}\text { Tratados com costunolida e eremanthin }(20 \mathrm{mg} / \mathrm{kg} / 60 \text { dias }) \text { apresentaram diminuição da glicemia } \\
\text { de forma dependente do tempo. }\end{array}$ \\
\hline & & tolerância oral à glicose em ratos & $\begin{array}{l}\text { Os ratos diabéticos tratados mostraram diminuição significativa }(\mathrm{p}<0,05) \text { no nível de glicose } \\
\text { plasmática após } 120 \text { e } 180 \text { min. }\end{array}$ \\
\hline & & TBARS & $\begin{array}{l}\text { A administração oral por } 60 \text { dias mostrou uma diminuição significativa }(p<0,05) \text { nos níveis de } \\
\text { TBARS nos tecidos. }\end{array}$ \\
\hline & & $\begin{array}{l}\text { Glutationa reduzida (GSH) e enzimas } \\
\text { antioxidantes em ratos }\end{array}$ & $\begin{array}{l}\text { Costunolida e eremanthin }(20 \mathrm{mg} / \mathrm{kg} \text { pc), houve um aumento no nível de GSH e da atividade } \\
\text { antioxidante enzimática }(\mathrm{P}<0,05) \text { e do cérebro, coração, fígado, pâncreas e rins. Esses resultados } \\
\text { foram significativos comparáveis aos da insulina. }\end{array}$ \\
\hline
\end{tabular}

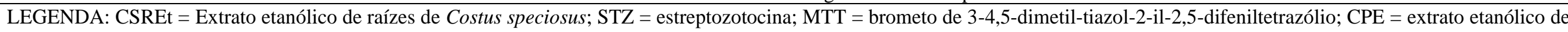

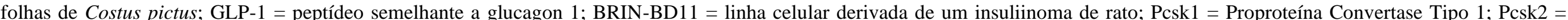

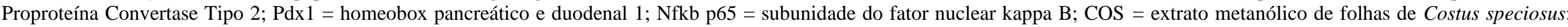

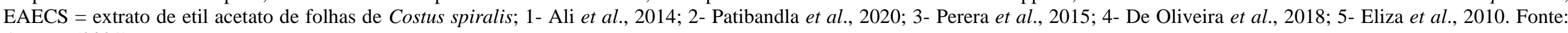
Autores (2021).

Tabela 5. Atividade urolítica de Costus arabicus e Costus spicatus.

\begin{tabular}{|c|c|c|c|}
\hline Espécie & Amostra & Modelo & Resultados obtidos \\
\hline C. arabicus $^{l}$ & EACA & $\begin{array}{l}\text { Efeito na cristalização de } \mathrm{CaOx} \\
\text { e a interação dos cristais de } \\
\mathrm{CaOx} \text { com o epitélio renal }\end{array}$ & $\begin{array}{l}\text { Diminuíram o crescimento dos cristais de uma forma dependente da concentração e o pré-revestimento de cristais com } \\
\text { EACA impediu sua adesão às células MDCK, enquanto o pré-tratamento das células não mostrou nenhum efeito. }\end{array}$ \\
\hline C. spicatus ${ }^{2}$ & ESCS & $\begin{array}{l}\text { Efeitos nefroprotetores e } \\
\text { antilitiaticos em um modelo pré- } \\
\text { clínico de lesão renal aguda e } \\
\text { nefrolitíase in vitro. }\end{array}$ & $\begin{array}{l}\text { Exerceu um efeito nefroprotetor significativo ao aumentar a excreção urinária de proteínas totais, uréia, creatinina, sódio, } \\
\text { potássio, cálcio e cloreto. Todos os grupos que foram tratados com ESCS exibiram uma redução de suas lesões } \\
\text { topatológicas e modulação significativa do estado redox do tecido. Também um efeito dependente da concentração na } \\
\text { cristalização dos cristais urinários, com redução do tamanho e proporção dos cristais monohidratados. }\end{array}$ \\
\hline
\end{tabular}

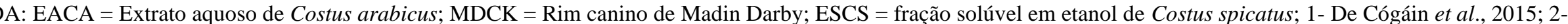

Moreno et al., 2021. Fonte: Autores (2021) 


\subsubsection{Atividade antimicrobiana}

Para confirmar os relatos de uso popular do gênero Costus, os extratos aquosos obtidos do caule e das folhas de Costus spiralis foram testados, em ensaio de disco-difusão em meio ágar sabouraud, contra duas espécies de Candida: $C$. albicans e C. parapsilosis, utilizando água destilada como controle negativo e Fluconazol como controle positivo. Os resultados expuseram que tais amostras não apresentaram atividade antifúngica para três concentrações testadas (Tabela 6) (Sousa, et al., 2018).

Outros relatos também demonstraram inatividade antifúngica dos extratos de diclorometano e de metanol de Costus spiralis contra C. albicans, Cryptococcus neoformans e Aspergillus ochraceou. Porém outras espécies pertencentes a Ordem Zingiberale apresentou atividades antifúngicas por conter constituintes menos polares como curcuminóides, pironas de kava e gingeróis isolados. Dessa forma, pode-se relacionar a maior polaridade do extrato aquoso a ineficácia da atividade antifúngica, uma vez que os compostos com atividade antifúngica foram extraídos com solvente de menor polaridade (Habsah et al., 2000; Sousa et al., 2018; Braga et al., 2007).

Para avaliar a atividade antimicrobiana e antifúngica de raízes Costus speciosus. Obteve-se primeiramente o óleo essencial a partir de raízes secas, o extrato metanólico e o extrato etanólico contendo diosgenina que foi isolado e epoxidado usando ácido m-cloroperbenzóico para produzir epóxido de diosgenina. Os resultados mostraram que o tratamento in vitro de fungos Microsporum gypseum, M. canis, Candida albicans pelo óleo essencial levou a rupturas de hifas e mudanças na forma dos esporos do fungo (Tabela 6). Os fungos filamentosos possuem como elemento constituinte básico a hifa, onde a partir dela formam-se esporos, para propagação das espécies. Nesse sentido, o óleo essencial estudado demonstra promissora atividade no controle da propagação dos fungos testados (Al-Kattan \& Khayyat, 2017; dos Santos \& Junior, 2015).

Os estudos sobre a atividade antimicrobiana mostraram alta inibição do crescimento de Pseudomonas aeruginosa e Staphylococcus aureus quando testados com extrato de óleo essencial. Os extratos de metanol e etanol exibiram um efeito inibitório sobre os fungos, leveduras e bactérias, enquanto o ingrediente epóxido de diosgenina constituinte do óleo apresentou maior atividade inibitória do crescimento in vitro do que a diosgenina contra M. gypseum, C. albicans e C. tropicalis. A atividade antimicrobiana de raízes de Costus speciosus contra os microrganismos testados pode estar associada com a presença de compostos fenólicos e da saponina diosgenina (Ariharan, Devi, Rajakokhila, \& Prasad, 2012; Al-Kattan \& Khayyat, 2017).

Ainda no que diz respeito aos rizomas da espécie Costus speciosus, o extrato de metanol total (TME), frações (FAECTME, FAETM, FCTME, FHCTME; Tabela 6) e diferentes extrativos, bem como os sesquiterpenos: lactona dehydrodihydrocostus (1), lactona dehidrocostus (2), arbusculina A (3), santamarina (4), reinosina (5) e ácido especioico (6) isolados das raízes foram avaliados quanto aos seus potenciais antimicrobianos. B. cereus teve seu crescimento inibido por TME, suas frações e os isolados 5 e 6, enquanto $C$. albicans teve seu crescimento inibido somente por TME, FCTME, FHCTME e o isolado 6. Os compostos 5 e 6 pertencem ao grupo de lactonas sesquiterpênicas, um dos maiores grupos de metabólitos secundários em plantas, sendo um dos principais mecanismos de defesa das plantas contra os ataques microbianos. As atividades dos extratos e frações podem estar associadas a diferença de solubilidade dos compostos presentes (Ibrahim, et al., 2019).

Quanto às bactérias $S$. aureaus e E. coli, a FCTME demonstrou efeito apenas conta o crescimento de $S$. aureaus. As concentrações mínimas dos compostos isolados foram avaliadas e o composto 6 demonstrou o melhor desemprenho quando a concentração mínima necessária para atuar, sugerindo que o mesmo possui desempenho promissor como agente antimicrobiano (Ibrahim, et al., 2019).

Em um terceiro estudo avaliando atividade antimicrobiana de raízes de Costus speciosus. Os extratos em diferentes polaridades de solventes orgânicos demonstraram inibição das bactérias $S$. aureus, S. epidermidis e B. subtilis, assim como nos fungos T. mentagrophytes, E. floccosum, T. rubrum e M. grisea. Para avaliação da concentração mínima para inibição foram 
utilizados somente os compostos costunolida e eremanthin que foram eficientemente inibidores de fungos, mas a atividade antibacteriana não foi significativa para os dois metabólitos isolados (Tabela 6; Duraipandiyan, et al., 2012).

Percebe-se, ao decorrer dos três últimos estudos abordados que a ação antimicrobiana das raízes da espécie Costus speciosus depende da polaridade do solvente utilizado na extração, onde quanto menos polar, mais compostos são extraídos e desempenham atividade antimicrobiana (Martins, Lopes \& Andrade, 2013). Além disso, os compostos isolados diosgenina (Al-Kattan \& Khayyat, 2017), reinosina, ácido especioico (Ibrahim, et al., 2019), costunolida e eremanthin (Duraipandiyan, et al., 2012) mostraram efeito significativamente maior em todos os estudos quando comparados aos extratos testados, demonstrando potencial promissor da espécie na atividade antimicrobiana.

Quanto à espécie Costus arabicus, os extratos etanólicos de caules e de suas folhas não foram eficientes e suficientes para cepas de Escherichia coli e Staphylococcus aureus com CIM entre 12 e $\geq 1.024 \mathrm{mg} / \mathrm{mL}$. Todavia, quando os extratos foram combinados em concentração subinibitória (CIM= 8-64 mg/mL) com os antibióticos gentamicina, canamicina, amicacina e neomicina houve uma intensificação dos seus efeitos, em que o extrato etanólico acabou apresentando sensibilidade para cepas Gram-negativas. Há de ser ressaltado que houve efeito fototóxico do extrato etanólico das folhas contra $E$. coli e $S$. aureus, mas foi inferior comparado a toxicidade do norfloxacino e 8-metoxipsoraleno Tais resultados inferem que essa espécie possa atuar de forma sinérgica com outros antibacterianos já utilizados na prática clínica, principalmente em casos de bactérias multidroga-resistentes. (Tabela 6; Coutinho, Costa, Lima, Falcão-Silva \& SiqueiraJúnior, 2010; Cunha, et al., 2011). 
Tabela 6. Atividade antimicrobiana de Costus arabicus, Costus speciosus e Costus spiralis.

\begin{tabular}{|c|c|c|c|}
\hline Espécie & Amostra & Modelo & Resultados \\
\hline \multirow[t]{2}{*}{ C. arabicus $^{1}$} & \multirow[t]{2}{*}{ EELC; EESC } & $\begin{array}{l}\text { Teste antibacteriano e modulação da } \\
\text { atividade antibiótica (E. coli e } S \text {. } \\
\text { aureus) }\end{array}$ & $\begin{array}{l}\text { E. coli e } S \text {. aureus } \text { CIM entre } 512 \text { e }>1.024 \mathrm{mg} / \mathrm{mL} \text {, antibióticos + extratos }-\mathrm{CIM}=8-64 \mathrm{mg} / \mathrm{m} \text {; } \\
\text { EELC CIM= valor ( Gram-negativa multirresistente) }\end{array}$ \\
\hline & & Ensaio fototóxico & EELC $<$ ativo norfloxacina e 8-metoxipsoraleno. \\
\hline \multirow{10}{*}{ C. speciosus $^{2}$} & \multirow[t]{2}{*}{ HERCS } & Difusão de disco com bactérias & $\begin{array}{l}\text { Halo }(\mathrm{mm})=S . \text { aureus }=15 / 2,5 \mathrm{mg} / \text { disco, } \text { S. } \text { epidermidis: } 15 / 5 \mathrm{mg} / \text { disco e } B . \text { subtilis }=12 / 2,5 \\
\mathrm{mg} / \text { disco. }\end{array}$ \\
\hline & & Difusão de disco com fungos & $\begin{array}{l}\text { Inibiu significativamente o crescimento de } T \text {. mentagrophytes a } 0,125 \mathrm{mg} / \mathrm{mL}, \text { E. floccosum a } 0,250 \\
\mathrm{mg} / \mathrm{mL}, T \text {. rubrum a } 0,125 \mathrm{mg} / \mathrm{mL} \text { e } M \text {. grisea a } 0,125 \mathrm{mg} / \mathrm{mL}\end{array}$ \\
\hline & \multirow[t]{2}{*}{ CERCS } & Difusão de disco com bactérias & $\begin{array}{l}\text { Halo }(\mathrm{mm}) \text { S. aureus }=12 / 2,5 \mathrm{mg} / \mathrm{disco}, \text { S. epidermidis }=13 / 2,5 \mathrm{mg} / \mathrm{disco} \text { e } B . \text { subtilis }=9 / 5 \\
\mathrm{mg} / \mathrm{disco} .\end{array}$ \\
\hline & & Difusão de disco com fungos & Inibiu moderadamente o crescimento de fungos testados \\
\hline & EAERCS & $\begin{array}{l}\text { Difusão de disco com bactérias } \\
\text { Difusão de disco com fungos }\end{array}$ & $\begin{array}{l}\text { Halo }(\mathrm{mm}) S . \text { aureus }=10 / 5 \mathrm{mg} / \text { disco, } S . \text { epidermidis }=9 / 5 \mathrm{mg} / \mathrm{disco} \text { e } \text { B. subtilis }=9 / 5 \mathrm{mg} / \mathrm{disco} \text {. } \\
\text { Inibiu moderadamente o crescimento de fungos testados }\end{array}$ \\
\hline & \multirow[t]{2}{*}{ MERCS } & Difusão de disco com bactérias & $\begin{array}{l}\text { Halo }(\mathrm{mm})=S . \text { aureus }=14 / 2,5 \mathrm{mg} / \mathrm{disco}, \text { S. } \text { epidermidis }=12 / 2,5 \mathrm{mg} / \mathrm{disco} \text { e } B . \text { subtilis }=10 / 5 \\
\mathrm{mg} / \mathrm{disco} .\end{array}$ \\
\hline & & Difusão de disco com fungos & Inibiu moderadamente o crescimento de fungos testados \\
\hline & \multirow{2}{*}{ WERCS } & Difusão de disco com bactérias & Não inibiu nenhuma bactéria testada \\
\hline & & Difusão de disco com fungos & Não inibiu nenhum fungo testado. \\
\hline & $\begin{array}{l}\text { Costunolide; } \\
\text { Eremanthin }\end{array}$ & Microdiluição & 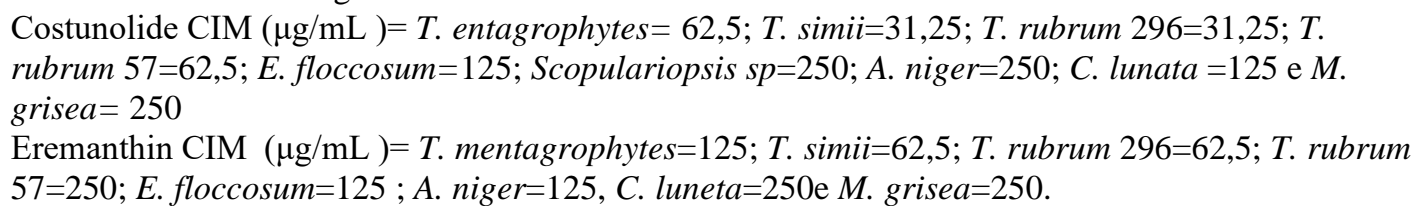 \\
\hline \multirow{7}{*}{ C. speciosus ${ }^{3}$} & TME & \multirow{6}{*}{$\begin{array}{l}\text { Difusão de disco com bactérias e } \\
\text { fungos }\end{array}$} & Halo $(\mathrm{mm})$ B. cereus $=13 ;$ C. albicans $=15$ \\
\hline & FAECTME & & Halo $(\mathrm{mm}):$ B. cereus $=13$ \\
\hline & FAETM & & Halo $(\mathrm{mm}):$ B. cereus $=13$ \\
\hline & FCTME & & Halo $(\mathrm{mm}):$ S. aureus e B. cereus $=11$ e $19 ;$ C. albicans $=12$ \\
\hline & FHCTME & & Ação moderada contra $B$. cereus e $C$. albicans \\
\hline & \multirow{2}{*}{$\begin{array}{l}\text { Compostos isolados: } \\
\text { diidrodehy } \\
\text { drocostusiactone (1), } \\
\text { desidrocostuslactona } \\
\text { (2), arbusculin A (3), } \\
\text { santamarine (4), } \\
\text { reynosin (5) e ácido }\end{array}$} & & $\begin{array}{l}5 \text { e } 6 \text { efeito em B. cereus; } 6 \text { promissor contra } C \text {. albicans. Demais não mostrou atividade ou fraca em } \\
\text { r Candida. }\end{array}$ \\
\hline & & Microdiluição bactéria e fungos & $\begin{array}{l}\text { CIM }(\mu \mathrm{g} / \mathrm{mL})-5 \mathrm{em} \text { B. cereus }=385 ; 6 \mathrm{em} \text { S. aureus }>150 ; \text { E. coli }=400 ; \text { B. cereu }=550 \text { e } C \text {. } \\
\text { albicans }=320\end{array}$ \\
\hline
\end{tabular}


especioico (6)

Óleo essencial bruto

C. speciosus $^{4}$

Extrato metanólico

Epóxido de

diosgenina
Extrato etanólico

Halo $(\mathrm{mm}):$ M. gypseum $=85 ;$ M. canis $=85 ;$ C. albicans $=85$, Pseudomonas aeruginosa $\cong 100$, Strephyloccus aureus $=60$

Halo $(\mathrm{mm}):$ M.gypseum $=85 ;$ M. canis $=75 ;$ C. albicans $=80$, P. aeruginosa $=60$, Strephyloccus aureus $=50$.

Halo $(\mathrm{mm}):$ M.gypseum $=76 ;$ M. canis $=82 ;$ C. albicans $=25$

Halo $(\mathrm{mm})$ : Microsporum gypseum $=85 ;$ M. canis $=79 ;$ C. albicans $=62$, Pseudomonas aeruginosa $=50$ Strephyloccus aureus $=60 \mathrm{~mm}$.

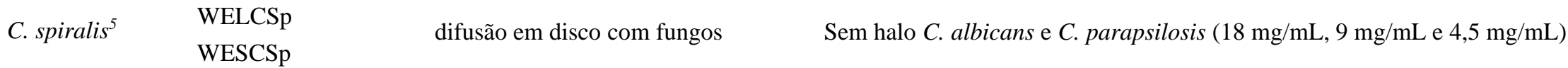

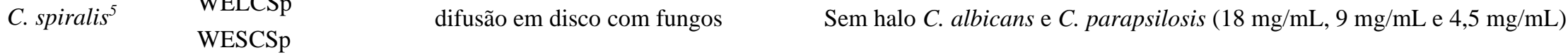

$\begin{array}{llll}\text { C. } \text { spiralis }^{5} & \text { WELCSp } & \text { difusão em disco com fungos } & \text { Sem halo C. albicans e C. parapsilosis }(18 \mathrm{mg} / \mathrm{mL}, 9 \mathrm{mg} / \mathrm{mL} \text { e } 4,5 \mathrm{mg} / \mathrm{mL})\end{array}$

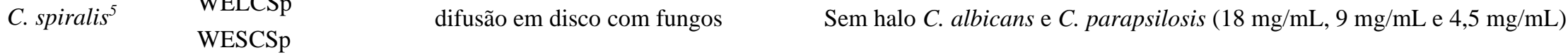

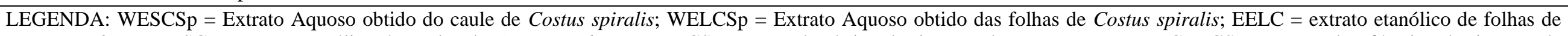

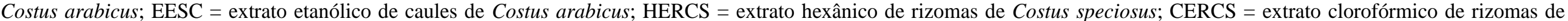

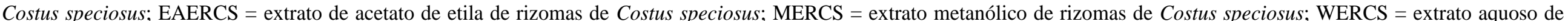

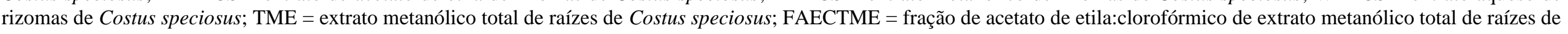

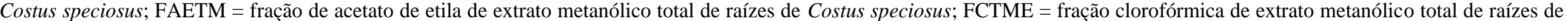

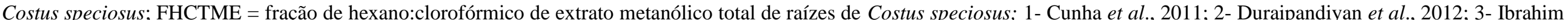
et al., 2019; 4- Al-Kattan \& Khayyat, 2017; 5- Sousa et al., 2018. Fonte: Autores (2021). 


\section{Considerações Finais}

O gênero demonstrou atividades promissoras nos cenários de inflamação e de diabetes induzida. As espécies presentes na maioria dos estudos avaliados foram Costus speciosus, Costus spiralis e Costus spicatus, sendo a primeira espécie com a maior quantidade de estudos realizados.

$\mathrm{Na}$ atividade anti-inflamatória, atribui-se seus efeitos a presença de compostos antioxidantes cujo mecanismos não foram completamente elucidados. Os testes realizados em ratos mostraram efeitos anti-inflamatório in vivo, o que suporta o uso de plantas do gênero no tratamento de afecções inflamatórias, entretanto são necessários mais estudos para que possam descrever detalhadamente aspectos toxicológicos das espécies do gênero, assegurando sua segurança para fins terapêuticos.

$\mathrm{Na}$ atividade antidiabética, todas as espécies estudadas demonstraram efeitos hipoglicêmico e antioxidante em ratos com diabetes induzida, dando suporte ao uso de plantas do gênero no controle glicêmico e na prevenção de complicações advindas da diabetes. Entretanto, assim como na atividade anti-inflamatória, reitera-se a necessidade de estudos toxicológicos para assegurar a segurança dos usuários e então desenvolver estudos que avaliem as espécies em humanos.

$\mathrm{Na}$ atividade urolítica, as espécies testadas demonstraram bons resultados quanto ao tratamento de nefrolitíase, mas há a necessidade de mais experimentos em modelos humanos para que sua ação local seja avaliada.

$\mathrm{Na}$ atividade antimicrobiana contra fungos, as espécies testadas não demonstraram efeitos promissores quanto aos seus extratos, sendo o óleo essencial de Costus speciosus a amostra com maior efeito antifúngico. Por outro lado, contra bactérias, extratos de menor polaridade demonstraram atividade relevante, assim como os compostos isolados testados. Não foi possível interpretar os mecanismos de ação envolvidos a esses compostos, mas sugere-se que possam contribuir na terapêutica juntamente com outros fármacos antimicrobianos. Portanto, conclui-se que o gênero Costus possui relevância medicinal com estudos que suportam o uso popular, confirmando atividades biológicas das espécies, porém ainda são necessários outros ensaios que avaliem a segurança dos compostos presentem nas espécies do gênero para futuros ensaios clínicos.

\section{Agradecimentos}

Os autores deste trabalho gostariam de agradecer ao Programa de Educação Tutorial da Faculdade de Farmácia da Universidade Federal do Pará pela oportunidade de aprendizagem com o grupo e suporte para a realizar desse estudo.

\section{Referências}

Ariharan, V. N., Devi, V. M., Rajakokhila, M., \& Prasad, P. N. (2012). Antibacterial activity of Costus speciosus rhizome extract on some pathogenic bacteria. International journal of advanced life sciences, 1(4).

Afonso, V., Champy, R., Mitrovic, D., Collin, P., \& Lomri, A. (2007). Reactive oxygen species and superoxide dismutases: role in joint diseases. Joint bone spine, 74(4), 324-329.

Al-Attas, A. A., El-Shaer, N. S., Mohamed, G. A., Ibrahim, S. R., \& Esmat, A. (2015). Anti-inflammatory sesquiterpenes from Costus speciosus rhizomes. Journal of ethnopharmacology, 176, 365-374.

Ali, H. A., Almaghrabi, O. A., \& Afifi, M. E. (2014). Molecular mechanisms of anti-hyperglycemic effects of Costus speciosus extract in streptozotocininduced diabetic rats. Saudi medical journal, 35(12), 1501.

Al-Kattan, M. O., \& Khayyat, S. A. (2017). Antimicrobial activity and Chemical analyses of oil constituents of Medicinal Plant Costus speciosus (Koen.).

Anyasor, G. N., Onajobi, F. D., Osilesi, O., \& Adebawo, O. (2015). Hematological and lipid profile evaluation of a hexane fraction of Costus afer leaves in arthritic rats. Pharmaceutical biology, 53(11), 1671-1676.

Anyasor, G. N., Onajobi, F., Osilesi, O., Adebawo, O., \& Oboutor, E. M. (2014). Anti-inflammatory and antioxidant activities of Costus afer Ker Gawl. hexane leaf fraction in arthritic rat models. Journal of ethnopharmacology, 155(1), 543-551.

Araújo, F. P. D., \& Oliveira, P. E. (2007). Biologia floral de Costus spiralis (Jacq.) Roscoe (Costaceae) e mecanismos para evitar a autopolinização. Brazilian Journal of Botany, 30(1), 61-70. 
Barbosa, J. H., Oliveira, S. L., \& Seara, L. T. (2008). O papel dos produtos finais da glicação avançada (AGEs) no desencadeamento das complicações vasculares do diabetes. Arquivos Brasileiros de Endocrinologia \& Metabologia, 52(6), 940-950.

Barbosa, K. B. F., Costa, N. M. B., Alfenas, R. D. C. G., De Paula, S. O., Minim, V. P. R., \& Bressan, J. (2010). Estresse oxidativo: conceito, implicações e fatores modulatórios. Revista de nutrição, 23(4), 629-643.

Benevides, C. M. de J. ., Costa, C. C. M. ., Cardoso, Y. P. ., Lopes, M. V. ., Montes, S. de S. ., \& Souza, A. C. dos S. . (2020). Heat treatment effect study on bioactive compounds of unconventional food plants. Research, Society and Development, 9(11), e46691110045. https://doi.org/10.33448/rsd-v9i11.10045

Braga, F. G., Bouzada, M. L. M., Fabri, R. L., Matos, M. D. O., Moreira, F. O., Scio, E., \& Coimbra, E. S. (2007). Antileishmanial and antifungal activity of plants used in traditional medicine in Brazil. Journal of ethnopharmacology, 111(2), 396-402.

Brasil (1999). Lei n 9.782, de 26 de janeiro de 1999: Define o Sistema Nacional de Vigilância Sanitária, cria a Agência Nacional de Vigilância Sanitária e dá outras providências. Diário Oficial da União, 1(18).

Cavalcanti, D. R., \& Albuquerque, U. P. (2013). The "hidden diversity" of medicinal plants in northeastern Brazil: diagnosis and prospects for conservation and biological prospecting. Evidence-Based Complementary and Alternative Medicine, 2013.

Brasil (2019). Cartilha de Plantas Medicinais e Fitoterápicos. (4th ed.). Conselho Regional de Farmácia do Estado de São Paulo.

Coutinho, M. A., Muzitano, M. F., \& Costa, S. S. (2009). Flavonoides: Potenciais agentes terapêuticos para o processo inflamatório. Revista Virtual de Química, 1(3), 241-256.

Coutinho, H. D. M., Costa, J. G. M., Lima, E. O., Falcão-Silva, V. S., \& Siqueira-Júnior, J. P. (2010). Increasing of the Aminoglicosyde Antibiotic Activity Against a Multidrug-Resistant E. coli by Turnera ulmifolia L. and Chlorpromazine. Biological Research For Nursing, 11(4), 332-335.

Cunha, A. (org). (2014). Farmacognosia e Fitoquímica. $4^{\mathrm{a}}$ ed. Lisboa: Fundação Calouste Gulbenkian

Cunha, F. A., Matias, E. F., Brito, S. V., Ferreira, F. S., Braga, J. M. A., Costa, J. G., \& Coutinho, H. D. (2011). In vitro antibacterial, phototoxic, and synergistic activity of ethanol extracts from Costus cf. arabicus L. Journal of medicinal food, 14(9), 964-968.

da Conceição Santos, R., da Silva Lima, V., do Nascimento Nunes, J. V., Feitosa, J. M., Ramos, R. M., da Silva Siqueira, J., Ferreira, L. R. D., de Lima, A. R. $\&$ da Silva, G. C. (2020). Aspectos biológicos do gênero Costus com enfâse na Costus spiralis. Brazilian Journal of Development, $6(10), 78703-78716$.

da Silva, B.P., \& Parente, J.P. (2003). Bioactive polysaccharides from Costus spicatus. Carbohydr Polym. 51:239-242.

de Cógáin, M. R., Linnes, M. P., Lee, H. J., Krambeck, A. E., de Mendonça Uchôa, J. C., Kim, S. H., \& Lieske, J. C. (2015). Aqueous extract of Costus arabicus inhibits calcium oxalate crystal growth and adhesion to renal epithelial cells. Urolithiasis, 43(2), $119-124$.

de Farias Silva, D., Simões Bezerra, P. H., Lopes de Sousa Ribeiro, L., Viana, M., de Lima, A. A., da Silva Neto, G. J., Teix eira, C. S., Machado, S. S., Alexandre Moreira, M. S., Delatorre, P., Campesatto, E. A., \& Rocha, B. (2021). Costus spiralis (Jacq.) Roscoe leaves fractions have potential to reduce effects of inflammatory diseases. Journal of ethnopharmacology, 268.

de Oliveira, A. P., Coppede, J. S., Bertoni, B. W., Crotti, A. E., França, S. C., Pereira, A. M. S., \& Taleb-Contini, S. H. (2018). Costus spiralis (Jacq.) Roscoe: A Novel Source of Flavones with $\alpha$-Glycosidase Inhibitory Activity. Chemistry \& biodiversity, 15(1), e1700421.

dos Santos, E. R. D., \& Junior, P. A. H. (2015). Material Complementar ao livro Sistemática Vegetal I: Fungos.

Decreto $\mathrm{N}^{\mathrm{o}}$ 5.813, de 22 de junho de 2006. (2006, 22 junho). Aprova a Política Nacional de Plantas Medicinais e Fitoterápicos e dá outras providências. Diário Oficial da União, Brasília.

Dinarello, C. A. (2000). Proinflammatory cytokines. Chest, 118(2), 503-508.

dos Santos, D., \& Farias Rodrigues, M. (2017). Atividades farmacológicas dos flavonoides: um estudo de revisão. Estação Científica (UNIFAP), 7(3), 29-35.

Duarte, R. C., Andrade, L. A., \& Oliveira, T. (2017). Revisão da planta Costus Spiralis (JACQ.) Roscoe: pluralidade em propriedades medicinais.

Duraipandiyan, V., Al-Harbi, N. A., Ignacimuthu, S., \& Muthukumar, C. (2012). Antimicrobial activity of sesquiterpene lactones isolated from traditional medicinal plant, Costus speciosus (Koen ex.Retz.) Sm. BMC complementary and alternative medicine, 12, 13. https://doi.org/10.1186/1472-6882-12-13

Egwunyenga, A. O., Isamah, G., \& Nmorsi, O. P. (2004). Lipid peroxidation and ascorbic acid levels in Nigeria children with acute falciparum malaria. African Journal of Biotechnology, 3(10), 560-563.

Eliza, J., Daisy, P., \& Ignacimuthu, S. (2010). Antioxidant activity of costunolide and eremanthin isolated from Costus speciosus (Koen ex. Retz) Sm. Chemico-Biological Interactions, 188(3), 467-472.

Habsah, M., Amran, M., Mackeen, M. M., Lajis, N. H., Kikuzaki, H., Nakatani, N., Rahman, A. A., Ghafar \& Ali, A. M. (2000). Screening of Zingiberaceae extracts for antimicrobial and antioxidant activities. Journal of ethnopharmacology, 72(3), 403-410.

Hitchon, C. A., \& El-Gabalawy, H. S. (2004). Oxidation in rheumatoid arthritis. Arthritis Res Ther, 6(6), 1-14.

Hopkins, S. J. (2003). The pathophysiological role of cytokines. Legal Medicine, 5, S45-S57.

Ibrahim, S. R. M., Ahmed El-Shaer, N. S. A., Asfour, H. Z., Elshali, K. Z., Awad Shaaban, M. I., Al-Attas, A. A. M., \& Allah Mohamed, G. A. (2019). Antimicrobial, antiquorum sensing, and antiproliferative activities of sesquiterpenes from Costus speciosus rhizomes. Pakistan Journal of Pharmaceutical Sciences, 32(1), 109-115. 
Just, M. J., Recio, M. C., Giner, R. M., Cullar, M. J., Manez, S., \& Bilia, A.R. (1998) Anti-inflammatory activity of unusual Lupane saponins from Bupleurum fruticescens. Planta Med., 64,404-407

Kracht, M., \& Saklatvala, J. (2002). Transcriptional and post-transcriptional control of gene expression in inflammation. Cytokine, 20(3), 91-106.

Krishnan, K., Mathew, L. E., Vijayalakshmi, N. R., \& Helen, A. (2014). Anti-inflammatory potential of $\beta$-amyrin, a triterpenoid isolated from Costus igneus. Inflammopharmacology, 22(6), 373-385.

Le Bars, D., Gozariu, M., \& Cadden, S. W. (2001). Animal models of nociception. Pharmacological reviews, 53(4), $597-652$.

Marcondes, J. A. M. (2003). Diabete melito: fisiopatologia e tratamento. Revista da Faculdade de Ciências Médicas de Sorocaba, 5(1), 18-26.

Martins, C. R., Lopes, W. A., \& Andrade, J. B. D. (2013). Solubilidade das substâncias orgânicas. Química Nova, $36(8), 1248-1255$.

Maurice, M. M., Nakamura, H., Van der Voort, E. A., Van Vliet, A. I., Staal, F. J., Tak, P. P., ... \& Verweij, C. L. (1997). Evidence for the role of an altered redox state in hyporesponsiveness of synovial T cells in rheumatoid arthritis. The Journal of Immunology, 158(3), 1458-1465.

Moreno, K. G. T., Junior, A. G., Dos Santos, A. C., Palozi, R. A. C., Guarnier, L. P., Marques, A. A. M., \& de Barros, M. E. (2021). Nephroprotective and antilithiatic activities of Costus spicatus (Jacq.) Sw.: Ethnopharmacological investigation of a species from the Dourados region, Mato Grosso do Sul State, Brazil. Journal of Ethnopharmacology, 266, 113409

Müller, T. D., Finan, B., Bloom, S. R., D'Alessio, D., Drucker, D. J., Flatt, P. R., Fritsche, A., Gribble, F., Grill, H. J., Habener, J. F., Holst, J. J., Langhans, W., Meier, J. J., Nauck, M. A., Perez-Tilve, D., Pocai, A., Reimann, F., Sandoval, D. A., Schwartz, T. W., Seeley, R. J., Stemmer, K., Tang-Christensen, M., Woods, S. C., DiMarchi, R. D., Tschöp, M. H. \& Tschöp, M. H. (2019). Glucagon-like peptide 1 (GLP-1). Molecular metabolism, $30,72-130$.

Oliveira, F., Akisue, G., \& Akisue, M. K. (2014). Farmacognosia identificação de drogas vegetais.

Opal, S. M., \& DePalo, V. A. (2000). Anti-inflammatory cytokines. Chest, 117(4), 1162-1172.

Paes, L. S., Mendonça, M. S., \& Casas, L. L. (2013). Aspectos Estruturais e fitoquímicos de partes vegetativas de Costus spicatus (Jacq.) Sw. (Costaceae). Revista Brasileira de Plantas Medicinais, 15(3), 380-390.

Patibandla, C., Khan, Z. I., MacGregor, L., Campbell, M. J., \& Patterson, S. (2020). Costus pictus D. Don leaf extract stimulates GLP-1 secretion from GLUTag L-cells and has cytoprotective effects in BRIN-BD11 $\beta$-cells. Journal of Ethnopharmacology, 260.

Pereira, A. S., Shitsuka, D. M., Parreira, F. J., \& Shitsuka, R. (2018). Metodologia da pesquisa científica.

Pereira, M. M., \& Bossolani, G. D. P. (2020). O uso de flavonoides no tratamento do diabetes mellitus tipo 2. Revista Saúde Viva Multidisciplinar da AJES, 3(4).

Perera, H. K. I., Premadasa, W. K. V. K., \& Poongunran, J. (2015). $\alpha$-glucosidase and glycation inhibitory effects of costus speciosus leaves. BMC complementary and alternative medicine, 16(1), 1-9.

Picanço, L. C. D. S., Bittencourt, J. A. H. M., Henriques, S. V. C., da Silva, J. S., Oliveira, J. M. D. S., Ribeiro, J. R., Sanjay, A. B., Carvalho, J. C. T., Stie, D. \& Silva, J. O. D. (2016). Pharmacological activity of Costus spicatus in experimental Bothrops atrox envenomation. Pharmaceutical biology, 54(10), 21032110

Quintans Junior, L. J., Santana, M. T., Melo, M. S., de Sousa, D. P., Santos, I. S., Siqueira, R. S., Lima, T. C., Silveira, G. O., Antoniolli, A. R., Ribeiro, L. A. A. \& Santos, M. R. (2010). Antinociceptive and anti-inflammatory effects of Costus spicatus in experimental animals. Pharmaceutical biology, 48(10), 10971102

Ribeiro, R. A., Vale, M. L., Thomazzi, S. M., Paschoalato, A. B., Poole, S., Ferreira, S. H., \& Cunha, F. Q. (2000). Involvement of resident macrophages and mast cells in the writhing nociceptive response induced by zymosan and acetic acid in mice. European journal of pharmacology, $387(1), 111-118$.

Rosak, C. (2002). The pathophysiologic basis of efficacy and clinical experience with the new oral antidiabetic agents. Journal of Diabetes and its Complications, 16(1), 123-132.

Riella, M. C. (2003). Princípios de nefrologia e distúrbios hidroeletrolíticos. In Princípios de nefrologia e distúrbios hidroeletrolíticos (pp. 1033-1033).

Sakurai, H., Kohsaka, H., Liu, M. F., Higashiyama, H., Hirata, Y., Kanno, K., Saito, I. \& Miyasaka, N. (1995). Nitric oxide production and inducible nitric oxide synthase expression in inflammatory arthritides. The Journal of clinical investigation, 96(5), 2357-2363.

Seo, W. D., Kim, J. H., Kang, J. E., Ryu, H. W., Curtis-Long, M. J., Lee, H. S., Yang, M. S. \& Park, K. H. (2005). Sulfonamide chalcone as a new class of $\alpha$ glucosidase inhibitors. Bioorganic \& medicinal chemistry letters, 15(24), 5514-5516.

Silva, M. B., Nicoli, A., Costa, A. S. V., Brasileiro, B. G., Jamal, C. M., Silva, C. A., Paula Júnior, T.J \& Teixeira, H. (2008). Ação antimicrobiana de extratos de plantas medicinais sobre espécies fitopatogênicas de fungos do gênero Colletotrichum. Revista Brasileira de Plantas Medicinais, 10(3), 57-60.

Singh, P., Khosa, R. L., Srivastava, S., Mishra, G., Jha, K. K., Srivastava, S., Sangeeta, Verma, R. K. \& Tahseen, M. A. (2014). Pharmacognostical study and establishment of quality parameters of aerial parts of Costus speciosus-a well known tropical folklore medicine. Asian Pacific journal of tropical biomedicine, 4(6), 486-491.

Soares, N., Santos, P., Vieira, V., Pimenta, V., \& Araújo, E. (2016). Técnicas de prospecção fitoquímica e sua importância para o estudo de biomoléculas derivadas de plantas. Enciclopédia Biosfera, 13(24). 
Research, Society and Development, v. 10, n. 8, e4410816902, 2021

(CC BY 4.0) | ISSN 2525-3409 | DOI: http://dx.doi.org/10.33448/rsd-v10i8.16902

Sousa, W. C., Rocha, J. D., Conceição, E. C. D., Almeida, L. M., Chen, L. C., Borges, L. L., \& Bailão, E. F. L. C. (2018). In vivo assessment of cyto/genotoxic, antigenotoxic and antifungal potential of Costus spiralis (Jacq.) Roscoe leaves and stems. Anais da Academia Brasileira de Ciencias, 90(2), 1565-1577.

Tak, P. P., Zvaifler, N. J., Green, D. R., \& Firestein, G. S. (2000). Rheumatoid arthritis and p53: how oxidative stress might alter the course of inflammatory diseases. Immunology today, 21(2), 78-82.

Valle, I. F. A. D. (2016). Análise do efeito dos flavonoides na resposta glicêmica e insulinêmica: uma revisão de literatura. 